\title{
Effect of Prior Oxidation on the Reduction Behavior of Magnetite-Based Iron Ore During Hydrogen- Induced Fluidized Bed Reduction
}

\author{
HENG ZHENG, DANIEL SPREITZER, THOMAS WOLFINGER, \\ JOHANNES SCHENK, and RUNSHENG XU
}

\begin{abstract}
Magnetite-based iron ore usually shows a high sticking tendency and a poor reducibility in the fluidized bed because of its dense structure. To enhance the fluidization and reduction behaviors of magnetite-based iron ore during hydrogen-induced fluidized bed reduction, the effect of a prior oxidation treatment is investigated. The results show that the untreated magnetite-based iron ore cannot be fluidized successfully in the tested temperature range between $600{ }^{\circ} \mathrm{C}$ and $800{ }^{\circ} \mathrm{C}$. At $600{ }^{\circ} \mathrm{C}$ reduction temperature, the de-fluidization can be avoided by a prior oxidation treatment. At higher reduction temperatures, the fluidization behavior can be further improved by an addition of 0.5 wt pct $\mathrm{MgO}$. Magnesiowüstite $\left(\mathrm{Fe}_{x} \mathrm{Mg}_{1-x} \mathrm{O}\right)$ is formed, which decreases the contact chance of the sticky surface between particles. Regarding to the reduction rate, a prior partial oxidation is more beneficial compared to deep oxidation. The kinetic analysis shows that $\mathrm{MgO}$ could promote the initial reaction. The reaction rate limiting step is no longer diffusion but chemical reaction for prior partly oxidized samples. A prior partial oxidation combined with an addition of $\mathrm{MgO}$ is considered to be a promising pretreatment method for a successful processing of magnetite-based iron ore.
\end{abstract}

https://doi.org/10.1007/s11663-021-02215-5

(C) The Author(s) 2021

\section{INTRODUCTION}

TODAY, the two dominating process routes for steelmaking are the blast furnace-basic oxygen furnace $(\mathrm{BF}-\mathrm{BOF})$ route and the scrap-based electric arc furnace $(\mathrm{EAF})$ route. $^{[1]}$ In order to achieve the goal of climate neutrality (net-zero greenhouse gas emissions) by 2050 , breakthrough technologies are crucial for further decreasing the overall $\mathrm{CO}_{2}$ emissions from steel production. ${ }^{[2,3]}$ One option is the use of $\mathrm{H}_{2}$ as a reducing agent to produce direct reduced iron (DRI), followed by a melting stage, typically an electric arc furnace for crude steel production (DRI-EAF). Currently, methane is commonly used to produce a syngas of $\mathrm{H}_{2}$ and $\mathrm{CO}$ as a reducing gas. In this case, if decarbonized electricity is

HENG ZHENG and DANIEL SPREITZER are with the Montanuniversitaet Leoben, Franz-Josef-Straße 18, 8700 Leoben, Austria. Contact e-mails: heng.zheng@stud.unileoben.ac.at; daniel.spreitzer@unileoben.ac.at THOMAS WOLFINGER is with the K1-MET GmbH, Stahlstraße 14, 4020 Linz, Austria. JOHANNES SCHENK is with the Montanuniversitaet Leoben and also with the K1-MET GmbH. RUNSHENG XU is with the State Key Laboratory of Refractories and Metallurgy, Wuhan University of Science and Technology, Wuhan 430081, China.

Manuscript submitted December 9, 2020; accepted April 23, 2021.

Article published online June 1, 2021. used, the greenhouse gas intensity of the DRI-EAF route can be decreased to around $0.7 \mathrm{t} \mathrm{CO}_{2} / \mathrm{t}$ steel. ${ }^{[4-6]}$ The amount of scrap return is supposed to increase within the next few years. As a result, the production of EAF steel will also grow, which requires a considerable amount of DRI product to produce high quality steel grades. ${ }^{[7,8]}$

The fluidized bed technology has been widely used since the 1950s for the production of DRI; it has been well developed in the past decades. $\mathrm{H}_{2}$ and iron ore fines can be used as a reducing gas and solid burden in the fluidized bed ironmaking process, respectively. ${ }^{[9]}$ Aside from hematite-based iron ores, the occurrence of magnetite-based iron ore is also very common in nature. The use of magnetite-based iron ore during hydrogen-induced fluidized bed reduction is therefore of great interest. As reported, it is impossible for magnetite-based iron ore fines guaranteeing a stable fluidization during the total reduction procedure. ${ }^{[10]}$ Reduction by $\mathrm{H}_{2}$ is an endothermal reaction; therefore, pre-heating of iron ore is one opportunity for ensuring a sufficient energy supply. Generally, the preheating process occurs in oxidizing atmosphere. As a result, the magnetite iron ore becomes oxidized. The oxidation of magnetite is an exothermic reaction which generates considerable heat, which is beneficial for reducing the primary energy input for pre-heating. 
Many researchers investigated the effect of pre-oxidation on the reduction behavior of titanomagnetite in a fixed bed. Eungyeul et al. ${ }^{[11,12]}$ conducted the reduction test using both $\mathrm{H}_{2}$ and $\mathrm{CO}$. It was found that although the initial surface area of pre-oxidized titanomagnetite was much lower than that of raw material, the reducibility was greatly enhanced due to the structural transformation from rhombohedral (titanohematite) to spinel cubic (titanomagnetite) during the reduction, which led to about 25 pct volume expansion resulting in open structures. Wang et al. ${ }^{[13]}$ did the reduction kinetic analysis of titanomagnetite iron ore and found that the chemical reaction controlled the early stage of the reaction, while the mechanism of later stage was considered to be diffusion controlled. After pre-oxidation treatment, the reduction was entirely controlled by the chemical reaction. The diffusion was no more the rate-limiting step due to the formation of micro-cracks which served as channels for the reducing gas.

The most common problem for the fluidized bed reduction was the de-fluidization phenomenon caused by sticking of the reduced metallic iron, which would decrease the reduction efficiency and make a process control of the system impossible. ${ }^{[14]}$ The reduction temperature, ${ }^{[15]}$ fluidizing gas ${ }^{[16]}$ and particle size distributions ${ }^{[17]}$ showed significant impacts on the fluidization behavior. In CO-induced fluidized bed, the bonding effect of iron whisker was the common cause for de-fluidization. ${ }^{[18,19]}$ The addition of $\mathrm{H}_{2}$ in $\mathrm{CO}$ could control the surface morphology of particles from fibrous/whisker shape to dense structure and improved the fluidization behavior significantly. ${ }^{[20]} \mathrm{In}_{2}$-induced fluidized bed, although there was no iron whisker on the surface, the newly generated iron resulted in the agglomeration of particles. ${ }^{[21]}$ In order to prevent de-fluidization, many researchers focused on the coating treatment of iron ore. Zhong et al. ${ }^{[22]}$ found the $\mathrm{MgO}$ was more effective to prevent de-fluidization, comparing with $\mathrm{CaO}$. Under the condition of $\mathrm{CO}-\mathrm{H}_{2}$ reducing gas mixture, $\mathrm{MgO}$ could insulate the contact of metallic iron between particles effectively, which decrease the particle stickiness. The same time, because of the deposition of $\mathrm{CO}$, part of the iron in the particle surface was converted to $\mathrm{Fe}_{3} \mathrm{C}$, which also helped to decrease the sticky tendency. ${ }^{[23]}$ Guo et al. ${ }^{[24,25]}$ discussed five different coating methods on $\mathrm{Fe}_{2} \mathrm{O}_{3}$ particles (briquetting-sintering method, high temperature injection method, powder method, slurry-sintering method and coprecipitation method) in the $\mathrm{H}_{2}$-induced fluidized bed. It is found that, if $\mathrm{MgO}$ addition is above $1.5 \mathrm{wt}$ pct, all the methods could help to keep a stable fluidization. The reason can be explained by the formation of $\mathrm{MgFe}_{2} \mathrm{O}_{4}$ on the particle surface, which shows a high melting point. An effective coating method was important for avoiding de-fluidization problem. In the coprecipitation method, the $\mathrm{Fe}_{2} \mathrm{O}_{3}$ particles are coated with $\mathrm{MgO}$ in the liquid solution of $\mathrm{Mg}(\mathrm{NO})_{3} \cdot 6 \mathrm{H}_{2} \mathrm{O}$ and $\mathrm{Na}_{2} \mathrm{CO}_{3}$ to get more effective and uniformly adsorption of $\mathrm{MgO}$ particles. ${ }^{[25]}$ From coprecipitation method, only 0.411 wt pct of coating $\mathrm{MgO}$ content was required to avoid the sticking problem. The inhibiting effect of $\mathrm{MgO}$ could be summarized as physical and chemical barrier. The main mechanism prevention of coating $\mathrm{MgO}$ at a reduction temperature below $800{ }^{\circ} \mathrm{C}$ was physical isolation. When the reduction temperature was above $900{ }^{\circ} \mathrm{C}$, the magnesia compounds $\left(\mathrm{Fe}_{2} \mathrm{MgO}_{4}\right.$ or $\mathrm{FeMgO}_{2}$ ) would appear on the surface which served as a chemical barrier. ${ }^{[26,27]}$

The above studies have explored the effects of pre-oxidation on the reduction and addition of $\mathrm{MgO}$ on fluidization behaviors. But the influences of prior oxidation treatment on magnetite-based iron ores are rarely discussed in $\mathrm{H}_{2}$-induced fluidization conditions. Currently, no general concept is available for a successful treatment of magnetite-based iron ore during hydrogen-induced fluidized bed reduction. The purpose of this study is to use magnetite-based iron ore directly as a raw material and to investigate methods preventing the de-fluidization. The present work aims at (1) a comparison of the fluidization behaviors between raw magnetite-based iron ore and oxidized one; (2) an examination of the reducibility of the raw and oxidized magnetite-based iron ore during the fluidized bed reduction; (3) an investigation of the effect of prior oxidation on improving the fluidization and reduction behaviors; (4) an analysis of the effect of $\mathrm{MgO}$ addition on the fluidization and reduction behaviors of the pre-oxidized magnetite-based iron ore; (5) a multistep kinetic analysis of the reduction mechanism of the magnetite-based iron ore. This work could provide precursory theoretical guidance for the pretreatment of magnetite-based iron ore for a successful $\mathrm{H}_{2}$-induced fluidized bed reduction.

\section{EXPERIMENTAL}

\section{A. Materials}

In this work, a commercial magnetite-based iron ore was used. The raw magnetite-based iron ore is defined as Sample A. The samples after deep and partial oxidation treatments were named Sample B and Sample C, respectively. The surface morphology of samples before reduction tests were shown in Figure 1. The raw magnetite-based iron ore fines had clear edges and corners, presenting irregular shapes. After oxidation, the sharp-edged corners disappear and the surface became less smooth, which provides more adsorption sites for the $\mathrm{MgO}$ powder. The particle size distribution of the samples consisted of $50 \mathrm{wt}$ pct $125-250 \mu \mathrm{m}$ and 50 wt pct $250-500 \mu \mathrm{m}$. The chemical compositions of the Sample A, Sample B and Sample C were characterized by the inductively coupled plasma-mass spectrometry (ICP-MS) method and listed in Table I. $\mathrm{MgO}$ powder with high purity was used in this work ( $>99.5$ wt pet, $-44 \mu \mathrm{m})$.

\section{B. Experimental apparatus and procedure}

The experimental apparatus used was a laboratory-scale fluidized bed reactor, which is schematically shown in Figure 2. The inner diameter of the reactor was $68 \mathrm{~mm}$. The upper part of the reactor was designed 

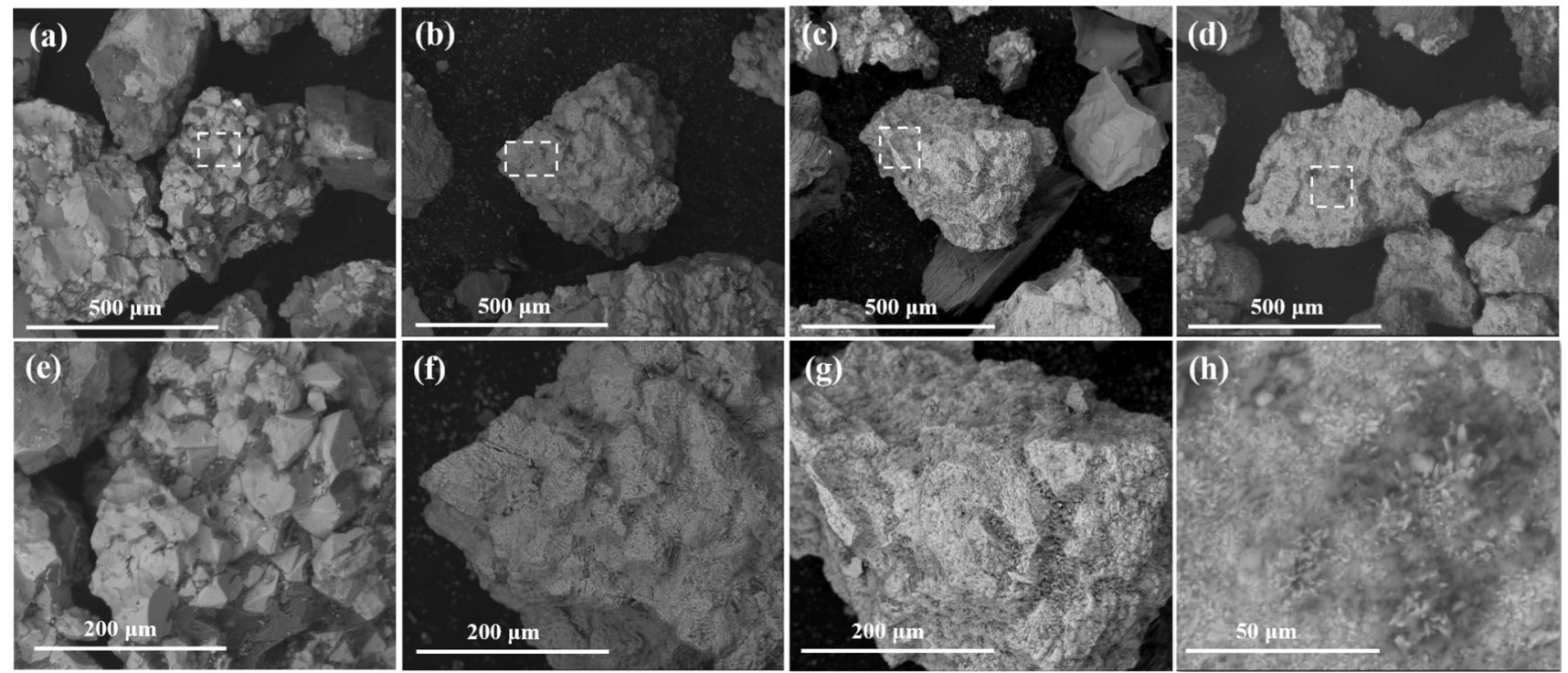

Fig. 1-Surface morphology of materials before reduction under SEM: $(a),(e)$ Sample A; $(b),(f)$ Sample B; $(c),(g)$ Sample C; $(d),(h)$ Sample B with additional 0.50 wt pet $\mathrm{MgO}$.

Table I. Chemical Compositions of the Samples (Wt Pet)

\begin{tabular}{lcccccccc}
\hline & $\mathrm{Fe}_{\text {tot }}$ & $\mathrm{FeO}$ & $\mathrm{SiO}_{2}$ & $\mathrm{Al}_{2} \mathrm{O}_{3}$ & $\mathrm{CaO}$ & $\mathrm{MgO}$ & $\mathrm{MnO}$ & $\mathrm{P}$ \\
\hline Sample A (Raw Magnetite) & 59.50 & 19.66 & 7.05 & 1.13 & 3.03 & 2.00 & 0.17 & 0.70 \\
Sample B (Deep Oxidized) & 57.80 & 0.50 & 6.84 & 1.11 & 2.97 & 1.96 & 0.17 & 0.68 \\
Sample C (Partially Oxidized) & 58.64 & 12.89 & 6.90 & 1.12 & 3.01 & 1.99 & 0.17 & 0.69 \\
\hline
\end{tabular}

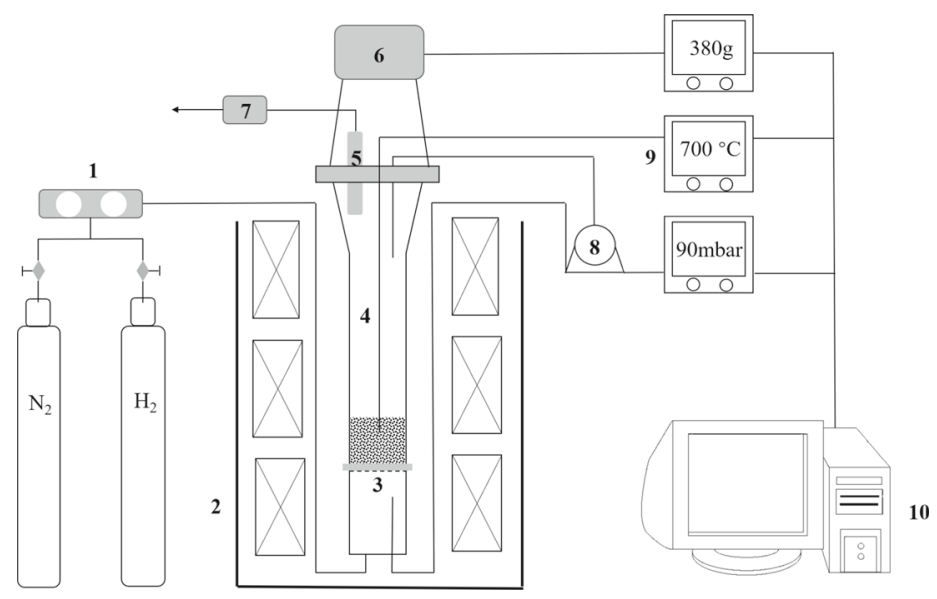

1. Gas mixture unit; 2. Three-stage electrical furnace; 3. Distributor; 4. Fluidized bed reactor; 5. Dust filter; 6. Scale;

7. Pressure regulator; 8. Differential pressure monitor; 9. Temperature control; 10. Computer system unit

Fig. 2-Schematic layout of laboratory fluidized bed reactor.

in a conical shape to reduce the superficial gas velocity and, therefore, to reduce the sample losses in the form of entrainment during fluidization. $\mathrm{H}_{2}$ and $\mathrm{N}_{2}$ were mixed in the gas mixing unit and preheated while passing through the supply pipe inside the furnace. The temperature of the reducing gas mixture and specimen temperature in the fluidized bed reactor were measured by thermocouples (Type $\mathrm{N}$ ) below the grid and inside the sample. These temperature measurements were used to control the power for the three-stage electrical resistance heating of the furnace. The three-stage heating system could work independently, which helped to maintain the reduction temperature. The sample temperature was measured by the thermocouple that inside the bed 
Table II. Experimental Process Conditions

\begin{tabular}{lccccc}
\hline Iron Ore & MgO Additive & Reducing Gas $\mathrm{H}_{2}$ & Gas Velocity & Temperature & Pressure \\
\hline $400 \mathrm{~g}$ & $0-1.5 \mathrm{wt}$ pct & $15.9 \mathrm{~L} / \mathrm{min}(\mathrm{SATP})$ & $0.4 \mathrm{~m} / \mathrm{s}$ & $600-800^{\circ} \mathrm{C}$ & $1 \mathrm{~atm}$. \\
\hline
\end{tabular}

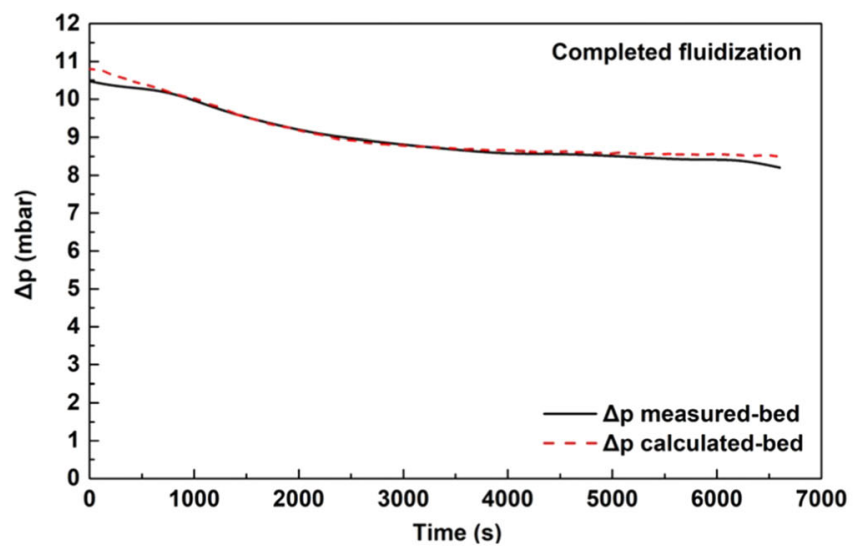

(a)

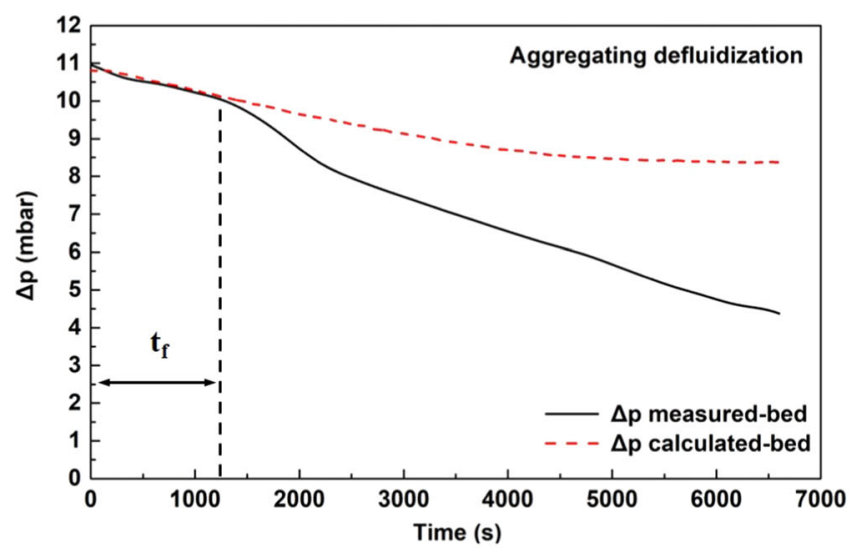

(c)

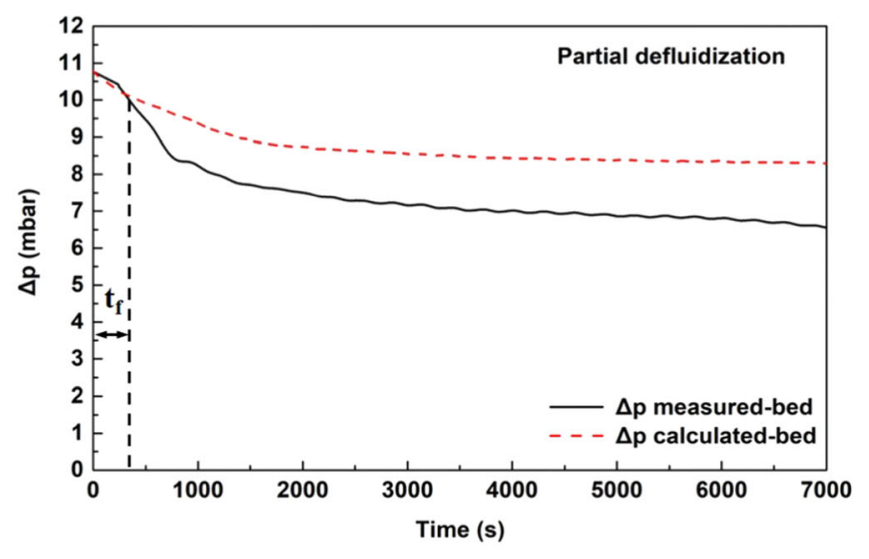

(b)

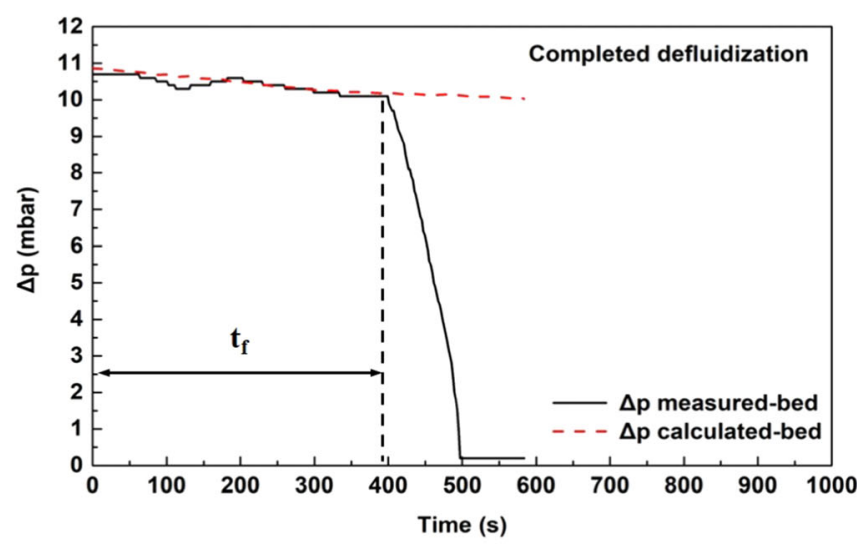

(d)

Fig. 3-Four states of fluidization behavior: $(a)$ completed fluidization; $(b)$ partial de-fluidization; $(c)$ aggregating de-fluidization; $(d)$ completed de-fluidization.

material. The fluidization behavior was characterized by the differential pressure measurement between the gas distributor and the material. The real-time pressure drop and weight change of the material were measured and these measurements were stored automatically by the system.

All reduction tests followed the same procedure. The material was charged through a small aperture at the top of the reactor at $500{ }^{\circ} \mathrm{C}$ during the preheating stage and purged with $\mathrm{N}_{2}$. When the material reached the target temperature, followed by a 10-minutes temperature equilibrium period, the atmosphere was changed to the reducing atmosphere. If de-fluidization occurred, or when the reaction time reached 110 minutes, the reducing gas was again replaced by $\mathrm{N}_{2}$ and sample cooling under $\mathrm{N}_{2}$ atmosphere began. The superficial gas velocity was kept constant at $0.4 \mathrm{~m} / \mathrm{s}$ at all different temperatures. This was achieved by a constant $\mathrm{H}_{2}$ flow rate, balanced by different nitrogen flow rates. The $\mathrm{H}_{2}$ was maintained as $15.9 \mathrm{~L} /$ minutes at standard ambient temperature and pressure (SATP).

The deep oxidation of magnetite iron ore was performed in a muffle furnace at $1000^{\circ} \mathrm{C}$ under air atmosphere for 20 hours to ensure a deep oxidation. The partial oxidation took place at $800{ }^{\circ} \mathrm{C}$ for 4 hours. The $\mathrm{MgO}$ particles were mixed directly with the material before charging it into reactor. The $\mathrm{MgO}$-content was represented by the weight percentage of $\mathrm{MgO}$ corresponding to the charged iron ore material. The experimental conditions are listed in Table II.

The weight loss measured during the reduction can be converted into the reduction degree (RD) by chemical analysis of the iron ore. The RD can be calculated based on Eqs. [1] through [3]: $[28,29]$ 


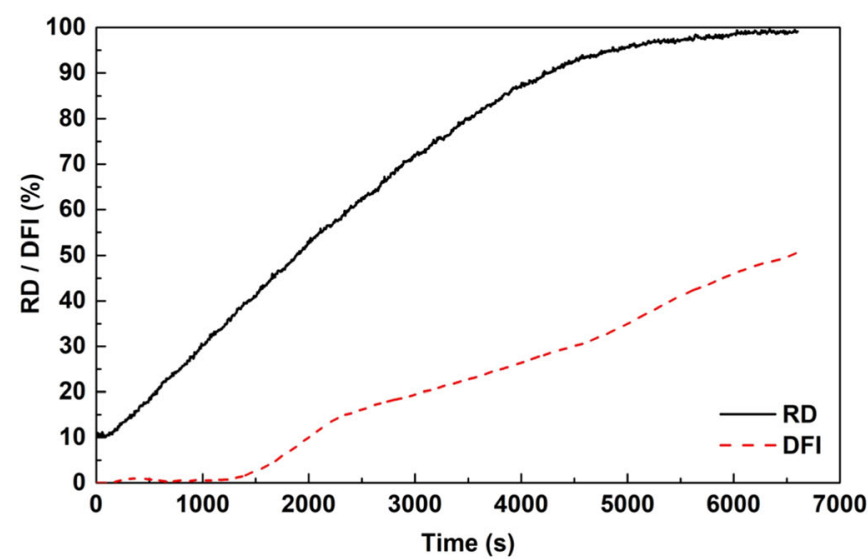

(a)

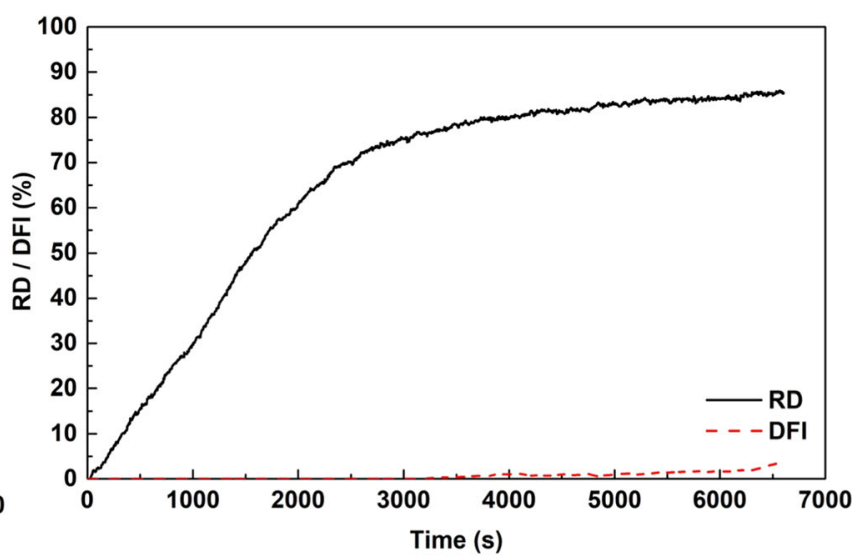

(b)

Fig. 4-Reduction degree and de-fluidization index of Sample A and Sample B at $600{ }^{\circ} \mathrm{C}:(a) \mathrm{RD} / \mathrm{DFI}$ of Sample A; (b) RD / DFI of Sample B.
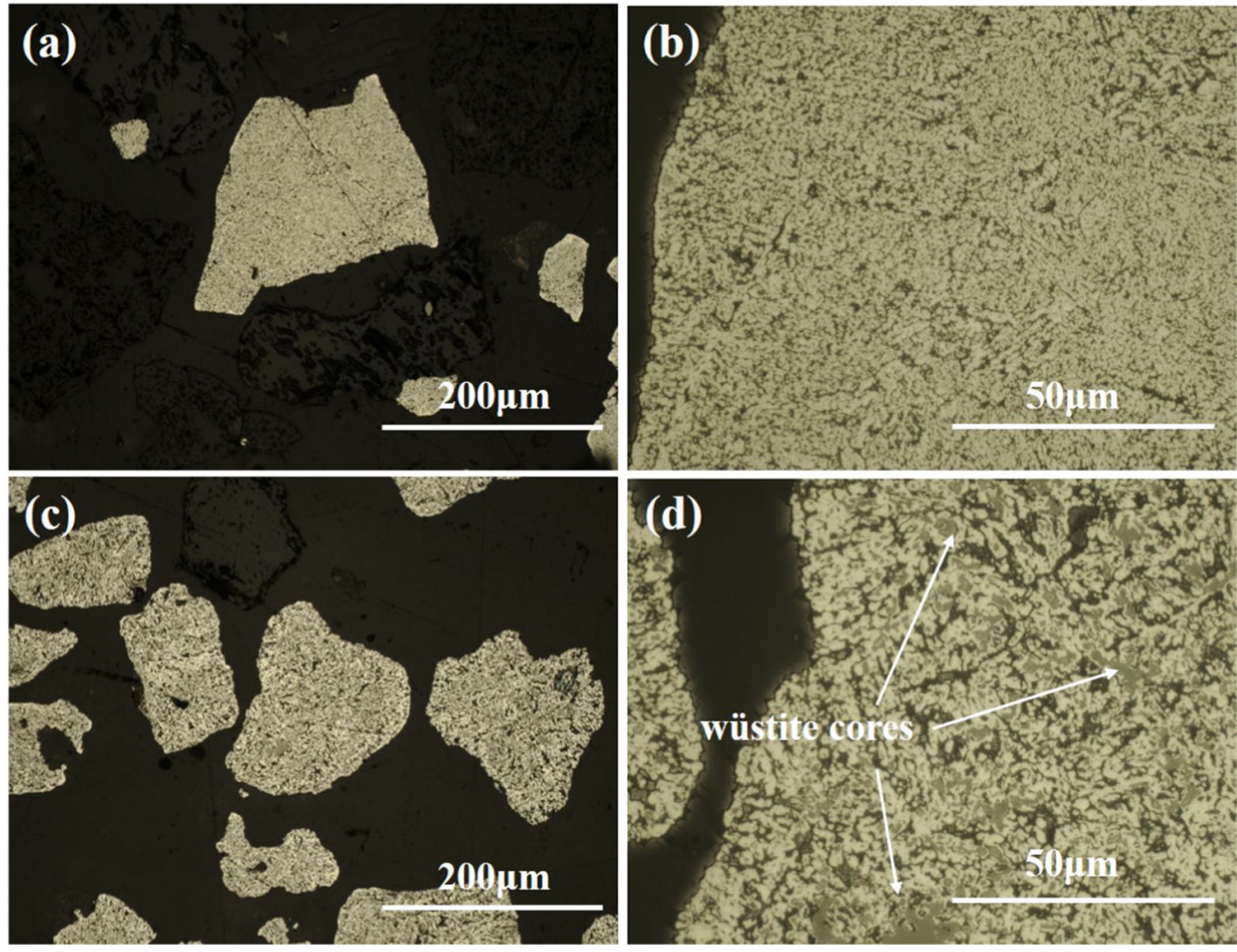

Fig. 5-Polished section images of the Sample A and Sample B after reduction tests at $600{ }^{\circ} \mathrm{C}$ under optical light microscope: $(a)$, $(b)$ Sample A; (c), (d) Sample B.

$$
\begin{gathered}
\mathrm{RD}=1-\frac{O_{\text {bounded to } \mathrm{Fe} \text { at } t=t i}}{O_{\text {bounded to Fe at } t=t 0}} \times 100 \text { pct, } \\
O_{\text {bounded to Fe at } t=t i}=\frac{O_{\text {bounded to } \mathrm{Fe}_{2} \mathrm{O}_{3}}+O_{\text {bounded to } \mathrm{FeO}}-\Delta m}{M_{\mathrm{O}}}(\text { in mol }),
\end{gathered}
$$

$$
O_{\text {bounded to Fe at } t=t 0}=1.5 \cdot \frac{m_{0} \cdot \mathrm{Fe}_{\mathrm{tot}}}{M_{\mathrm{Fe}}}(\text { in mol }),
$$

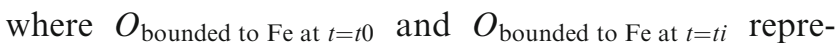
sent the amounts of $\mathrm{O}$ that are bounded to $\mathrm{Fe}$ at the start and during the reduction; $\Delta m$ and $m_{0}$ are the 


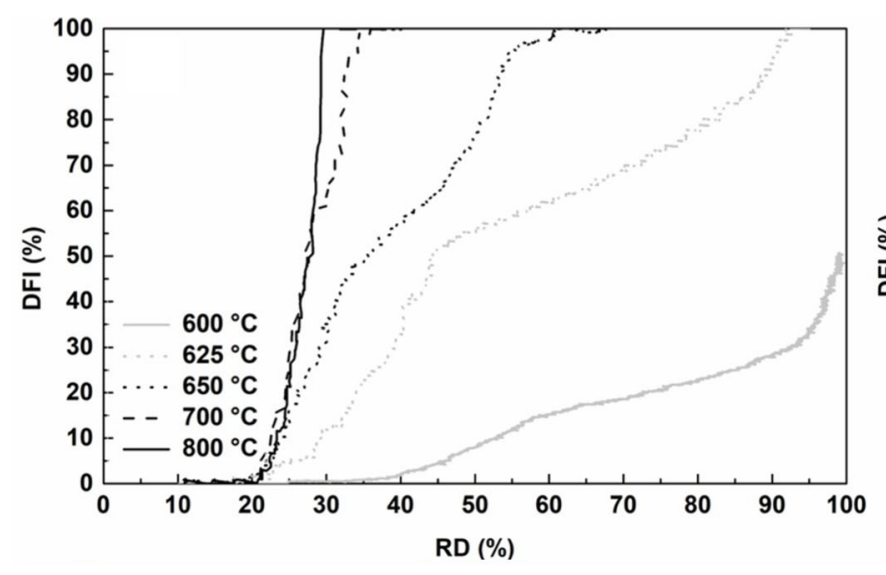

(a)

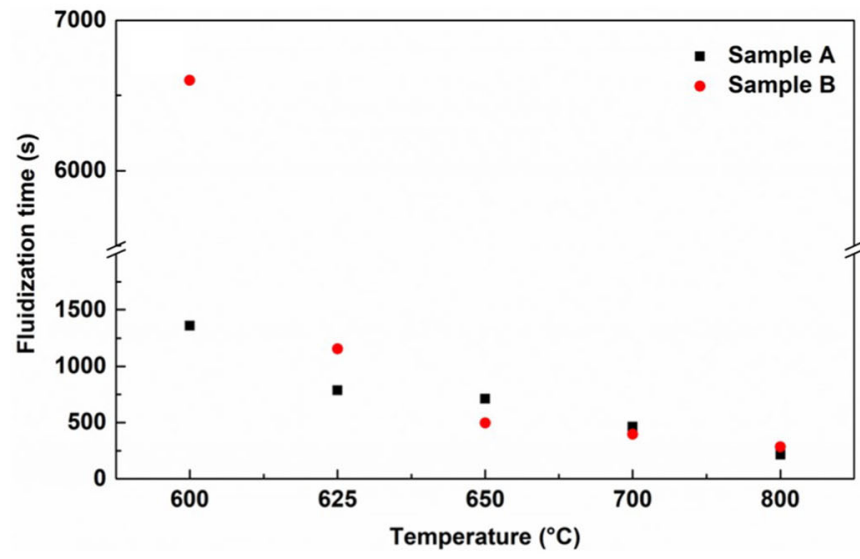

(c)

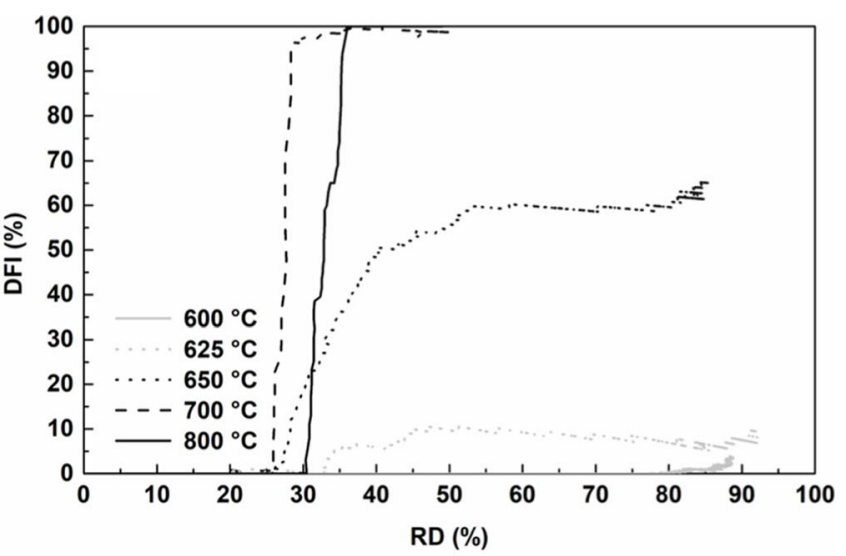

(b)

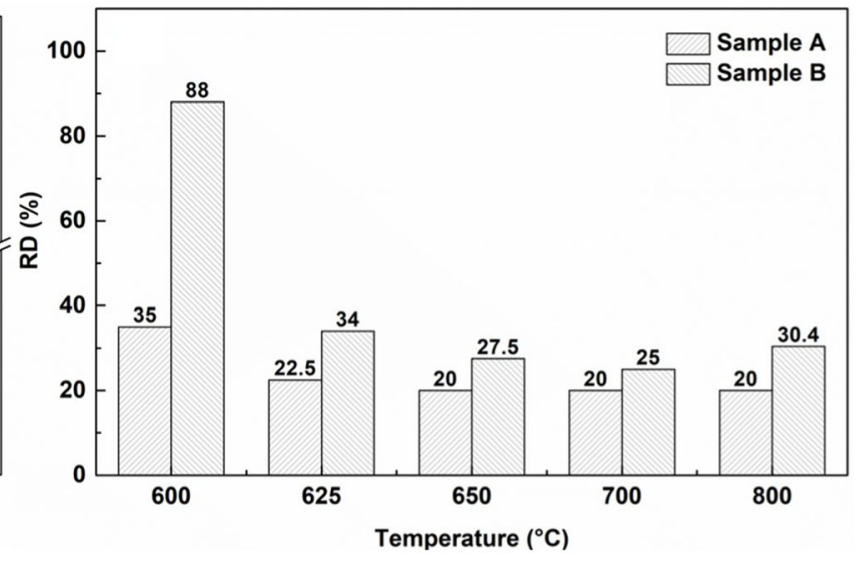

(d)

Fig. 6-Fluidization and reduction behaviors of Sample A and Sample B: (a) DFI of Sample A against RD; (b) DFI of Sample B against RD; (c) fluidization time; $(d)$ reduction degree when de-fluidization starts.

weight loss due to the loss of $\mathrm{O}$ and the mass of input material; $M_{\mathrm{O}}$ and $M_{\mathrm{Fe}}$ are the constant molar masses for $\mathrm{O}$ and $\mathrm{Fe}$.

\section{Determination of the Fluidization Behavior}

The fluidization behavior was characterized by the pressure drop measurement across the material during the test, which is explained in detail in previous publications. ${ }^{[8]}$ In the actual investigations, four typical curves of pressure drop were observed, which represent four types of fluidization states-namely, completed fluidization, partial de-fluidization, aggregating de-fluidization, and completed de-fluidization. Figure 3 shows exampled for the four pressure drop curves. The fluidization states can be summarized as follows:

(1) Completed fluidization (CF): The two lines are equal during the whole reduction, as shown in Figure 3(a).

(2) Partial de-fluidization (PD): The differential pressure decreases at the beginning and then remains stable afterwards, as shown in Figure 3(b).

(3) Aggregating de-fluidization (AD): The two lines are equal at the beginning. Then, the differential pressure decreases during the whole reduction, as shown in Figure 3(c).
Table III. Influence of Temperature on the Fluidization State

\begin{tabular}{lcc}
\hline & \multicolumn{2}{c}{ Fluidization State } \\
\cline { 2 - 3 } Reduction Temperature ${ }^{\circ} \mathrm{C}$ & Sample A & Sample B \\
\hline $600^{\circ} \mathrm{C}$ & AD & $\mathrm{CF}$ \\
$625^{\circ} \mathrm{C}$ & $\mathrm{CD}$ & $\mathrm{PD}$ \\
$650^{\circ} \mathrm{C}$ & $\mathrm{CD}$ & $\mathrm{PD}$ \\
$700^{\circ} \mathrm{C}$ & $\mathrm{CD}$ & $\mathrm{CD}$ \\
$800^{\circ} \mathrm{C}$ & $\mathrm{CD}$ & $\mathrm{CD}$ \\
\hline
\end{tabular}

(4) Completed de-fluidization (CD): The two lines are equal at the beginning. After a certain time, a sudden differential pressure drop occurs and turns to low values of pressure drop within quite a short time, representing a fixed bed, as shown in Figure $3(\mathrm{~d})$.

The fluidization time $\left(t_{\mathrm{f}}\right)$ can be determined as the duration when the dotted grey line $\left(\Delta p_{\text {calculated-bed }}\right)$ and the black line $\left(\Delta p_{\text {measured-bed }}\right)$ are distinguished from each other. The buoyancy force in this case was not considered. The $\Delta p_{\text {calculated-bed }}$ is assumed only because of the mass of the sample portion inside the fluidized 


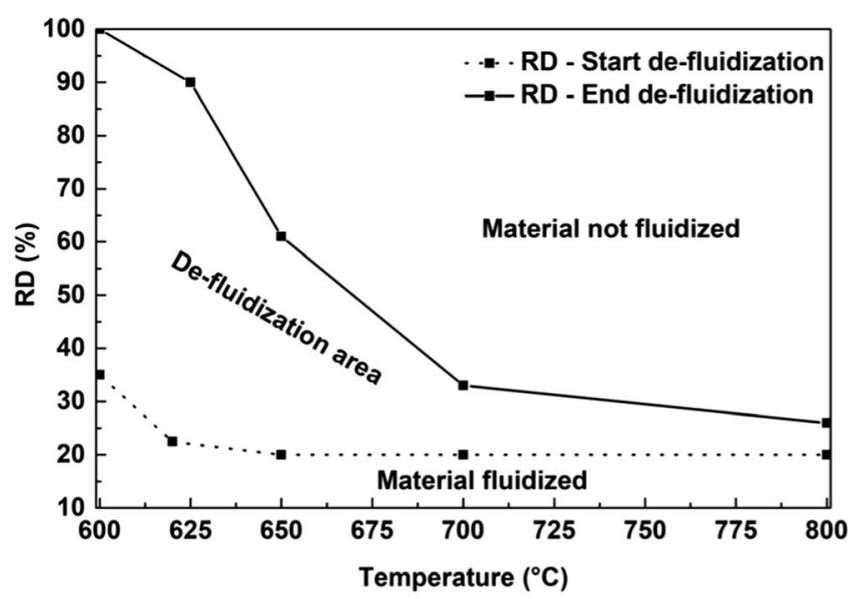

(a)

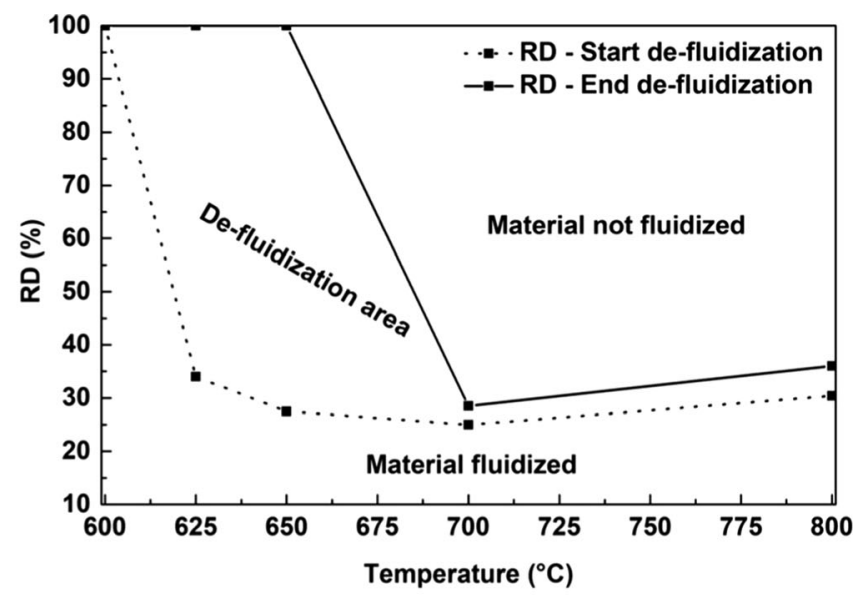

(b)

Fig. 7-Influence of temperature on the fluidization area: (a) Sample A, (b) Sample B.
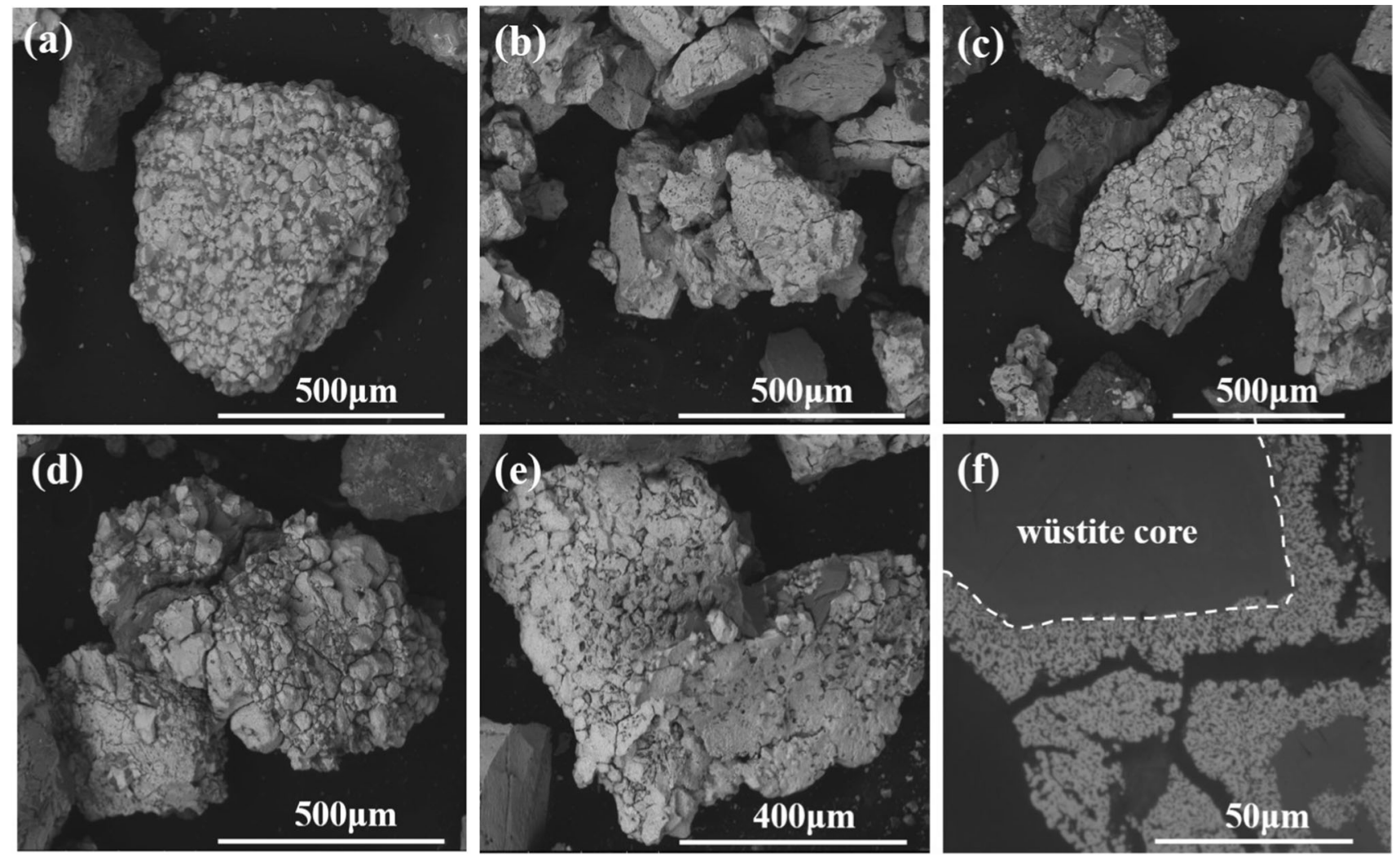

Fig. 8- Surface morphology of (partly) reduced Sample A, $\left(a\right.$ through $e$ ) are under SEM, $(f)$ is under optical light microscope: $(a) 600{ }^{\circ} \mathrm{C}$; $(b)$ $625^{\circ} \mathrm{C}$; (c) $650{ }^{\circ} \mathrm{C}$; (d) $700{ }^{\circ} \mathrm{C}$; (e) $800{ }^{\circ} \mathrm{C}$; (f) polished section from raw magnetite iron ore reduced in $650{ }^{\circ} \mathrm{C}$; (f) is reproduced with permission, ${ }^{[30]}$ copyright 2020 by Montanuniversität Leoben.

bed. To assess the fluidization during the experiment, a de-fluidization index (DFI), which describes the percentage of material, which is not fluidized, is defined as shown in Eq. [4].

$$
\mathrm{DFI}=\frac{\Delta p_{\text {calculated-bed }}-\Delta p_{\text {measured-bed }}}{\Delta p_{\text {calculated }- \text { bed }}-\Delta p_{\text {fixed }- \text { bed }}},
$$

$$
\Delta p_{\text {calculated-bed }}=\frac{m_{t} \cdot g}{\text { Rector area }}
$$

where $\Delta p_{\text {calculated-bed }}$ represents the theoretical differential pressure drop over material, which is calculated from the initial material mass and the weight loss sustained during the reduction if it is in a completed 

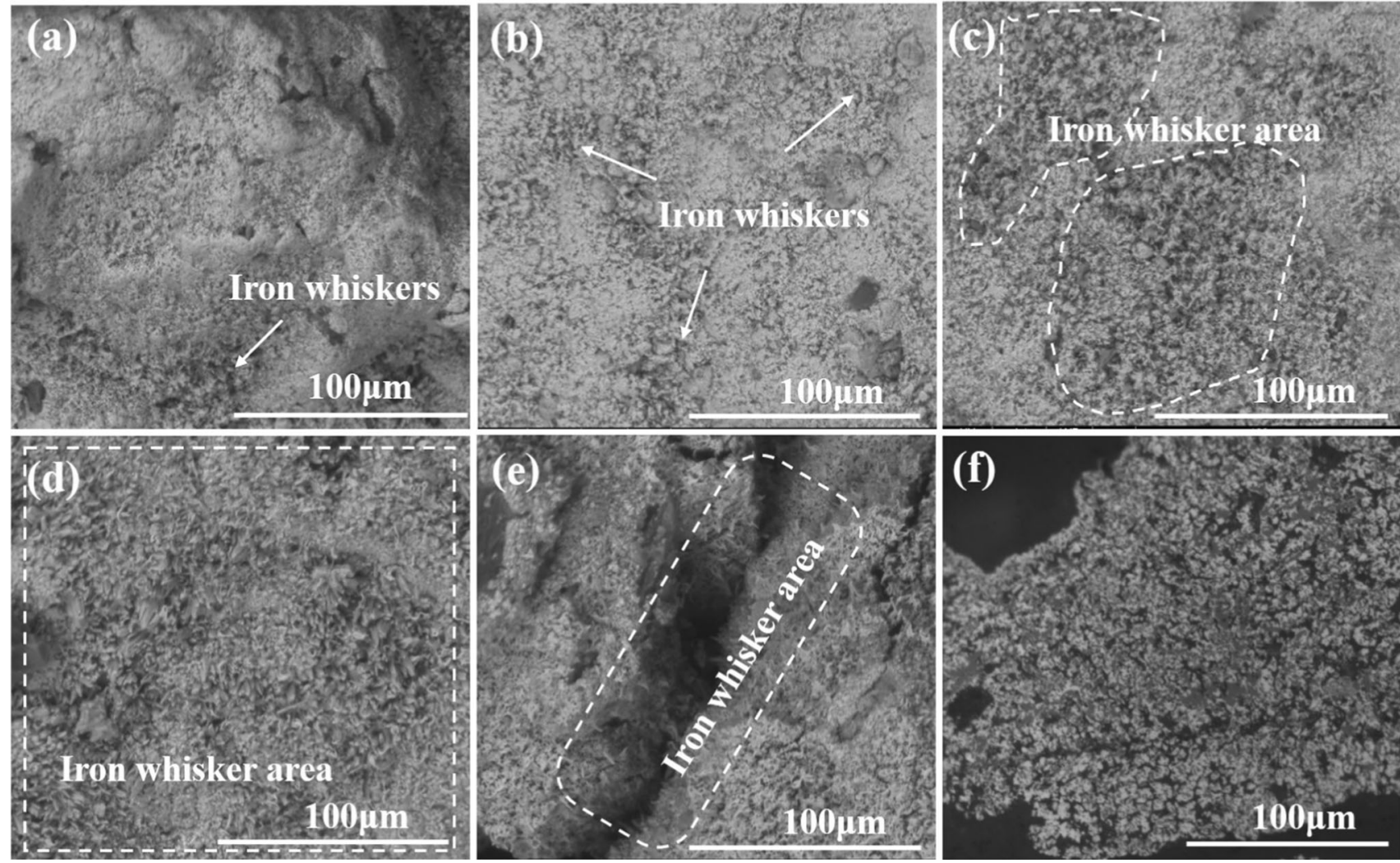

Fig. 9-Surface morphology of (partly) the reduced Sample B, $(a$ through $e)$ are under SEM, $(f)$ is under optical light microscope: (f) polished section for Sample B reduced in $650{ }^{\circ} \mathrm{C}$. (f) is reproduced with permission, ${ }^{[30]}$ copyright 2020 by Montanuniversität Leoben.

Table IV. Influence of MgO Addition on the Fluidization Behavior and the Final RD

\begin{tabular}{lcc}
\hline $\mathrm{MgO}$ Content (Wt Pct) & Fluidization State & Final Reduction Degree (Pct) \\
\hline 0 & CD & 25.00 \\
0.25 & PD & 91.37 \\
0.5 & CF & 93.75 \\
1.0 & CF & 96.05 \\
1.5 & CF & 96.35 \\
\hline
\end{tabular}

fluidized state; $m_{t}$ is the mass of the material during the reduction; $\Delta p_{\text {measured-bed }}$ represents the measured differential pressure drop for the material; the value of $\Delta p_{\text {fixed-bed }}$ is defined as when $\Delta p_{\text {measured-bed }}$ is smaller than 2 mbar referring to completed de-fluidization.

\section{Sample Characterization}

The polished micro section and the surface morphology of the samples were observed using an optical light microscope (Nikon MM 40 measuring microscope system, Japan) and a scanning electron microscopy (Quanta 200Mk2, FEI, America). The element distribution was analyzed by energy dispersive spectroscopy (EDS, Oxford Instrument, England). The XRD patterns were achieved by an D2phaser X-ray diffractometer (Bruker AXS GmbH, Germany) using Co as the X-ray source. The scanned angular range varied from 20 to $80 \mathrm{deg}$ with a scanning speed of $2^{\circ} / \mathrm{min}$.

\section{RESULTS AND DISCUSSION}

\section{A. Effect of Prior Deep Oxidation on the Fluidization and Reduction Behaviors of the Magnetite-Based Iron Ore}

Figure 4(a) shows the reduction results of Sample A and Sample B at $600{ }^{\circ} \mathrm{C}$ including the RD and DFI. The RD for Sample A always starts at $11 \mathrm{pct}$, because according to Eq. [1] magnetite is defined to have already a reduction degree of 11 pct. For Sample A, although de-fluidization starts at the reduction degree of 35 pct, indicated by the DFI, a complete reduction can be achieved within 110 minutes. Almost 50 pct of the Sample A is not in fluidized state at the end of the reduction. As shown in Figure 4(b), no de-fluidization occurs during the reduction of Sample B at $600{ }^{\circ} \mathrm{C}$. The reduction rate dramatically decreases when $\mathrm{RD}$ is higher than 80 pct. Figure 5 shows the polished section images of Sample A and Sample B after reduction. The particles 


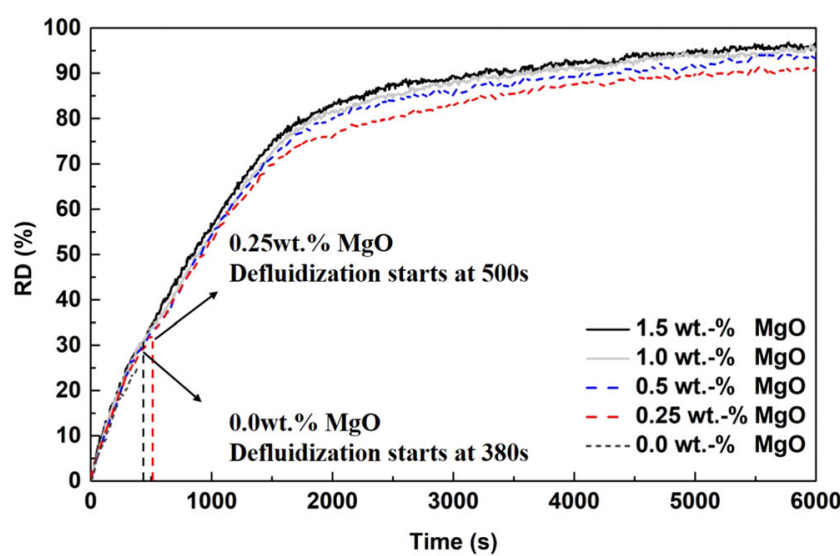

(a)

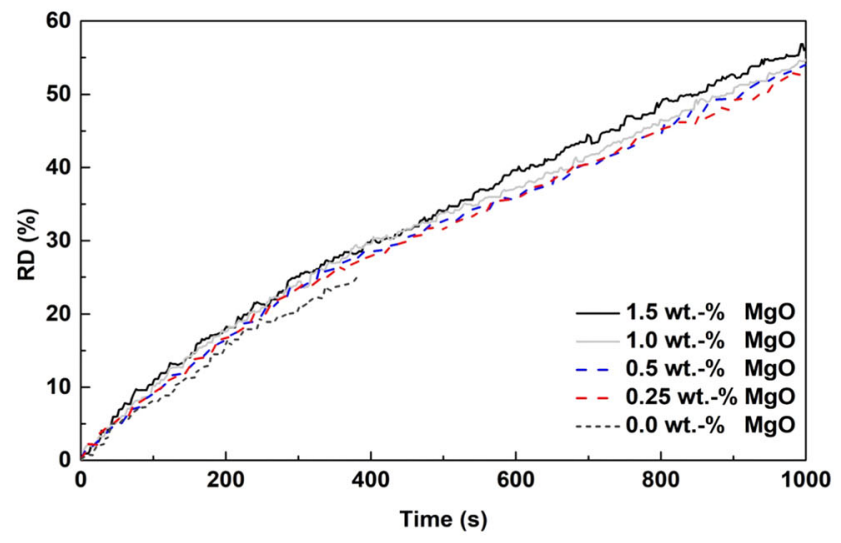

(c)

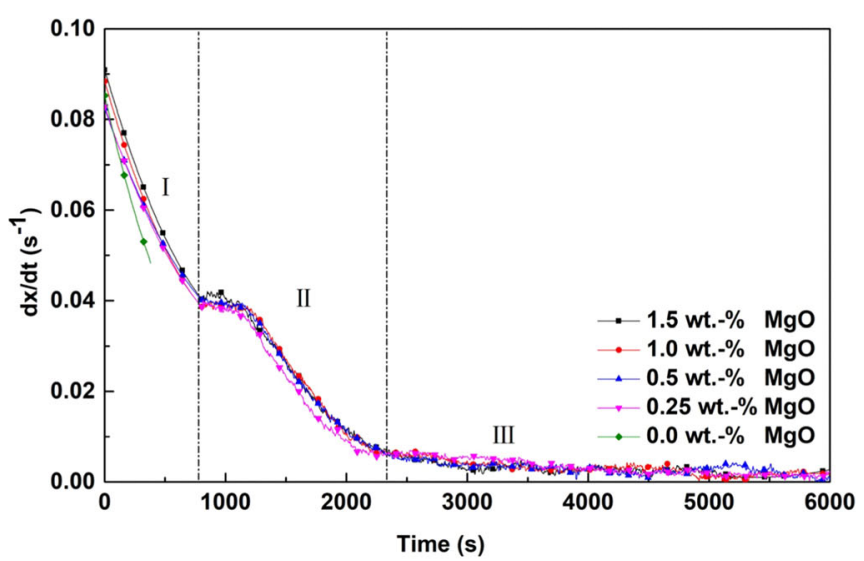

(b)

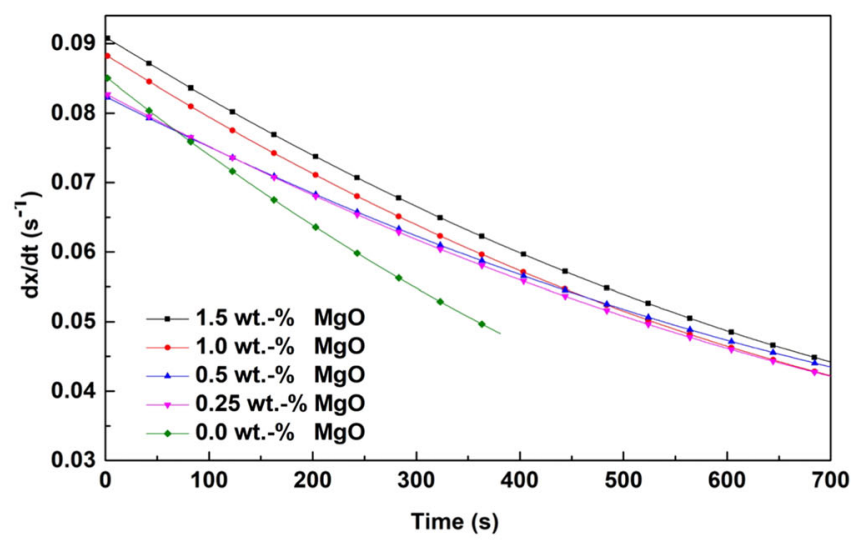

(d)

Fig. 10-Influence of $\mathrm{MgO}$ on reduction behavior: $(a),(c)$ reduction degree curves; $(b),(d)$ reduction rate.

in Sample A are completely reduced. However, in Sample B, small wüstite cores covered by iron shells can be observed inside the particles. The iron shells inhibit the direct contact of the reducing gas with the reaction interface, which explains the low reduction rate at the final stage.

The relationships between DFI, $t_{\mathrm{f}}, \mathrm{RD}$, and temperature are summarized in Figure 6. As given in Figure 6(a), for the Sample A, only at $600{ }^{\circ} \mathrm{C}$ reduction temperature a complete reduction can be achieved without de-fluidization problem. While for Sample B, as shown in Figure 6(b), the complete de-fluidization only occurred at temperatures higher than $700{ }^{\circ} \mathrm{C}$. The influence of temperature on $t_{\mathrm{f}}$ is significant, as shown in Figure 6(c). With increasing temperature, the $t_{\mathrm{f}}$ decrease, for both raw and oxidized magnetite-based iron ore. Figure 6(d) shows the relationship between reduction temperature and $\mathrm{RD}$ when de-fluidization starts. The RDs present a decreasing trend, along with the temperature, due to the short fluidization time. Combined with Figure 6(c), it can be seen that when the reduction temperature is above $650{ }^{\circ} \mathrm{C}$, even if the $t_{\mathrm{f}}$ of Sample B is smaller, the RDs are higher than those of Sample A. Especially at $800{ }^{\circ} \mathrm{C}$, the oxidized magnetite-based iron ore has similar $t_{\mathrm{f}}$ but shows nearly 10 pct higher RD, which indicates that the Sample B has a better reduction behavior in the initial stage. Previous researchers ${ }^{[31,32]}$ have confirmed that the reducibility of magnetite-based iron ore could be improved by pre-oxidation treatment; the results of this work are in agreement with their findings. It can be noted that if the temperature is higher than $700{ }^{\circ} \mathrm{C}$, the RD of the raw magnetite-based iron ore remains stable at 20 pct, which could be the critical RD for starting the de-fluidization. ${ }^{[33,34]}$ In actual case, metallic iron can be formed before the reduction to $\mathrm{FeO}$ completed, indicating that even RD is smaller than 33 pct the formation of first metallic could occur at the surface of the particles.

The fluidization states at different temperatures are shown in Table III. It can be seen that de-fluidization of Sample A occurs at all tested temperatures. The Sample $\mathrm{B}$ could maintain completed fluidization at $600{ }^{\circ} \mathrm{C}$ during the whole reduction test. However, with increasing temperature de-fluidization also takes place in the Sample B.

Based on the relations between temperature and RD, when de-fluidization starts and completes, a fluidization regime diagram can be defined, as shown in Figure 7. The area of completed de-fluidization expands with the increasing temperature. The starting points of de-fluidization of Sample B are higher than that of Sample A. In general, the effect of the prior oxidation treatment is 

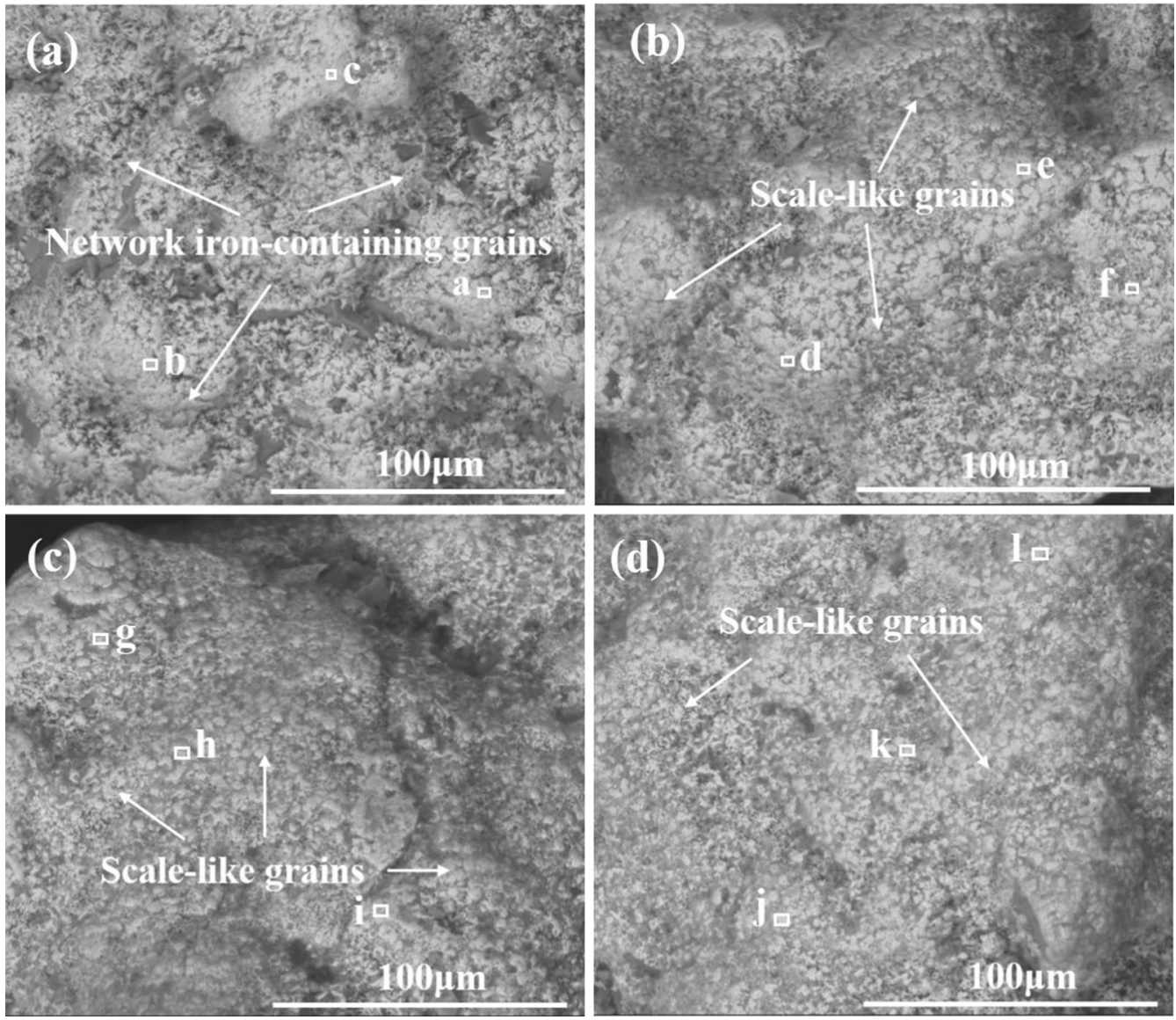

Fig. 11-Surface morphology of reduced Sample B with different amount of MgO under SEM: $(a) 0.25$ wt pct; (b) 0.50 wt pct; $(c) 1.00$ wt pct; (d) 1.50 wt pct.

beneficial for the fluidization behavior. It should be noted that, in Figure 7, de-fluidization starts or ends at RD equals 100 pct, which means that no de-fluidization or completed de-fluidization occur. At $600{ }^{\circ} \mathrm{C}$, the Sample B shows a completed fluidization state. Therefore, the start de-fluidization point of Sample B at $600{ }^{\circ} \mathrm{C}$ is set as 100 pct. At higher reduction temperature, it is not sufficient to ensure a stable fluidization by only prior oxidation treatment. $\mathrm{MgO}$ is a typical and effective additive that can be used preventing the de-fluidization phenomenon. ${ }^{[23-26]}$ Therefore, the effect of $\mathrm{MgO}$ on the fluidization behavior is discussed afterwards.

Figure 8 shows the surface morphology of Sample A after reduction at different temperatures. It can be seen that more and larger cracks appear on the particle surfaces with increasing reduction temperature. Although a crack formation occurs, the particles after reduction still have a dense structure. As shown in Figure 8(f), when reduction temperature is higher than $650{ }^{\circ} \mathrm{C}$, typical iron shells around the particles are formed and fewer pores exist in the remaining wüstite core. The de-fluidization of the Sample A happens due to the sticky precipitated iron shell. When the newly formed iron aggregates to certain content on the particle surface and iron shells are formed, the de-fluidization starts. $^{[21,35]}$
As shown in Figure 9, no cracks occur in Sample B after reduction. The pre-oxidation treatment promotes the formation of a porous structure during reduction, as shown in Figure 9(f). The porous structure does not only improve the reducibility, but also avoids the exclusive formation of metallic iron on the particle surface, thus decreasing the de-fluidization tendency. The iron is uniformly distributed in the whole particle area and the remaining wüstite can be also found throughout the whole particle. The formation of iron whiskers on the surface of the particles can be observed in Figures 9(a) through (e). The whisker usually occurred during the reduction from wüstite to iron. ${ }^{[36]}$ With increasing temperature, the iron whiskers become bigger and the whisker area expands. No precipitated iron shell, covering the particles, can be found in the particles of Sample B. Hence, the iron whiskers play an important role influencing the fluidization behavior during reduction. The whiskers can act as hooks between the particles, as it can be observed in Figure 9(e). The friction between the particles can be increased by the whiskers during fluidization, which requires a higher exertion force of the fluidization gas on the particles in order to break the newly formed connections. If the friction between the particles becomes too big, fluidization might be not possible anymore at given process conditions. The friction 
Table V. EDS Analysis With Different MgO Contents

\begin{tabular}{lllll}
\hline & 0.25 Wt Pct & 0.50 Wt Pct & 1.00 Wt Pct & 1.50 Wt Pct \\
& Point a, b, c & Point d, e, f & Point g, h, i & $53.38 \pm 3.83$ \\
\hline Fe, At. Pct & $69.19 \pm 3.02$ & $63.40 \pm 3.33$ & $59.81 \pm 3.55$ & $22.41 \pm 2.42$ \\
Mg, At. Pct & $11.39 \pm 1.05$ & $14.66 \pm 1.23$ & $16.61 \pm 0.91$ & $24.19 \pm 5.55$ \\
O, At. Pct & $19.41 \pm 3.99$ & $21.93 \pm 3.24$ & $23.57 \pm 2.84$ & \\
\hline
\end{tabular}

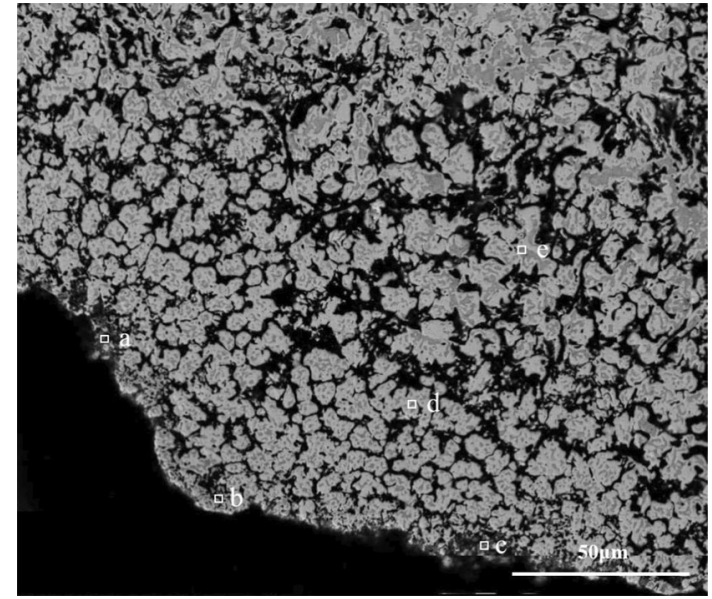

Fig. 12-Polished cross-section of Sample B with 1.5 wt pet $\mathrm{MgO}$ after reduction under SEM.

Table VI. EDS Analysis of Sample B With 1.5 Wt Pct MgO After Reduction

\begin{tabular}{lrrrll}
\hline & Point a & Point b & Point c & Point d & Point e \\
\hline Fe, At. Pct & 58.49 & 65.52 & 40.08 & 65.33 & 58.45 \\
Mg, At. Pct & 7.13 & 7.11 & 25.28 & 0 & 0 \\
O, At. Pct & 34.38 & 27.37 & 34.66 & 34.67 & 41.55 \\
\hline
\end{tabular}

becomes higher in case of a large quantity of such iron whiskers. That is why higher reduction degrees are required for Sample B to become de-fluidized.

\section{B. Effect of $\mathrm{MgO}$-Addition on the Fluidization and Reduction Behaviors of Deep Oxidized Magnetite Iron Ore}

The effect of $\mathrm{MgO}$-addition on the fluidization state and reducibility of Sample $\mathrm{B}$ was examined. The $\mathrm{MgO}$ powder was mixed with the oxidized magnetite-based iron ore before the reduction tests, which were conducted at $700{ }^{\circ} \mathrm{C}$. It can be seen in Table IV that if an $\mathrm{MgO}$ amount of $0.25 \mathrm{wt}$ pet is added, a partial de-fluidization occurs, with around 15 pct of the material not fluidized according to the DFI. De-fluidization can be avoided when the addition amount of $\mathrm{MgO}$ is higher than 0.25 wt pet. To demonstrate the influence of $\mathrm{MgO}$ on the reduction behavior, the relation between RD and $\mathrm{MgO}$-content is shown in Figure 10. With an increasing amount of $\mathrm{MgO}$, the reduction degree curves in Figure 10(a), moving slightly toward lower reduction times. It should be noted that with no and with 0.25 wt pct $\mathrm{MgO}$-addition, de-fluidization starts after a reduction time of $380 \mathrm{~s}$ and $500 \mathrm{~s}$, respectively. But only for the reduction tests without de-fluidization, the reduction degree and reduction rate are discussed and compared. Figure 10(b) shows the reduction rate for different values of $\mathrm{MgO}$ addition. The reduction rate can be divided into three stages (I, II, and III). Stage I is regarded as the fast reduction from $\mathrm{Fe}_{2} \mathrm{O}_{3}$ to $\mathrm{Fe}_{3} \mathrm{O}_{4}$. From Figure 10(d), it can be seen that samples with a higher amount of $\mathrm{MgO}$ exhibit a slightly higher reduction rate in Stage I. Combined with Figure 10(c), it seems that the $\mathrm{MgO}$ mainly has a promotion effect in Stage I. However, at further reduction, the reduction rate lines intertwine in Stages II and III and show no obvious pattern. The results are consistent with the previous researches from Muhammad ${ }^{[37]}$ and Srinivas ${ }^{[38]}$ that the addition of $\mathrm{MgO}$ could improve the reduction of $\mathrm{Fe}_{2} \mathrm{O}_{3}$. However, through molecular dynamics simulation, it is easier for $\mathrm{Mg}^{2+}$ to migrate to vacancy than $\mathrm{Fe}^{2+}$ in wüstite $(\mathrm{Fe} x \mathrm{O}){ }^{[39]}$ Therefore, magnesiowüstite $\left(\mathrm{Fe}_{x} \mathrm{Mg}_{1-x} \mathrm{O}\right)$ is formed, which inhibits the reduction of wüstite. The similar phenomenon is also found in the reduction of pure hematite doped with $\mathrm{MgO}$ using CO. ${ }^{[40]}$ EI-Geassy ${ }^{[40]}$ studied the influence of $\mathrm{MgO}$ on the stepwise reduction of pure hematite compacts. He found that in the hematite-magnetite reduction step the promotion effect occurred in the early stage because of an increase in porosity and an increase in active sites owing to the foreign cations into $\mathrm{Fe}_{2} \mathrm{O}_{3}$ lattice. At later stages, the formation of phase $\mathrm{MgO} \cdot \mathrm{Fe}_{2} \mathrm{O}_{3}$ with low reducibility retarded the reduction of $\mathrm{Fe}_{2} \mathrm{O}_{3}$. In the magnetite-wüstite and wüstite-iron reduction steps, the decreases in reduction rate was attributed to the formation of magnesiowüstite. In the present study, the final reduction degrees after 6000 seconds reduction time are listed in Table IV. Although Sample B with 0.25 wt pet $\mathrm{MgO}$-addition became partially de-fluidized, the final RD was as high as 91.37 pet. Generally, the addition of $\mathrm{MgO}$ shows a promotion effect on the reduction rete.

After reduction at $700{ }^{\circ} \mathrm{C}$, as shown in Figure 11, the surface of particles of the samples doped with different amounts of $\mathrm{MgO}$ have quite a smooth structure. The formation of iron whiskers cannot be observed, explaining the stable fluidization during the whole reduction procedure. Three EDS spots were conducted on every particle to obtain the composition of the surface region of the particles. The average result of element contents, 

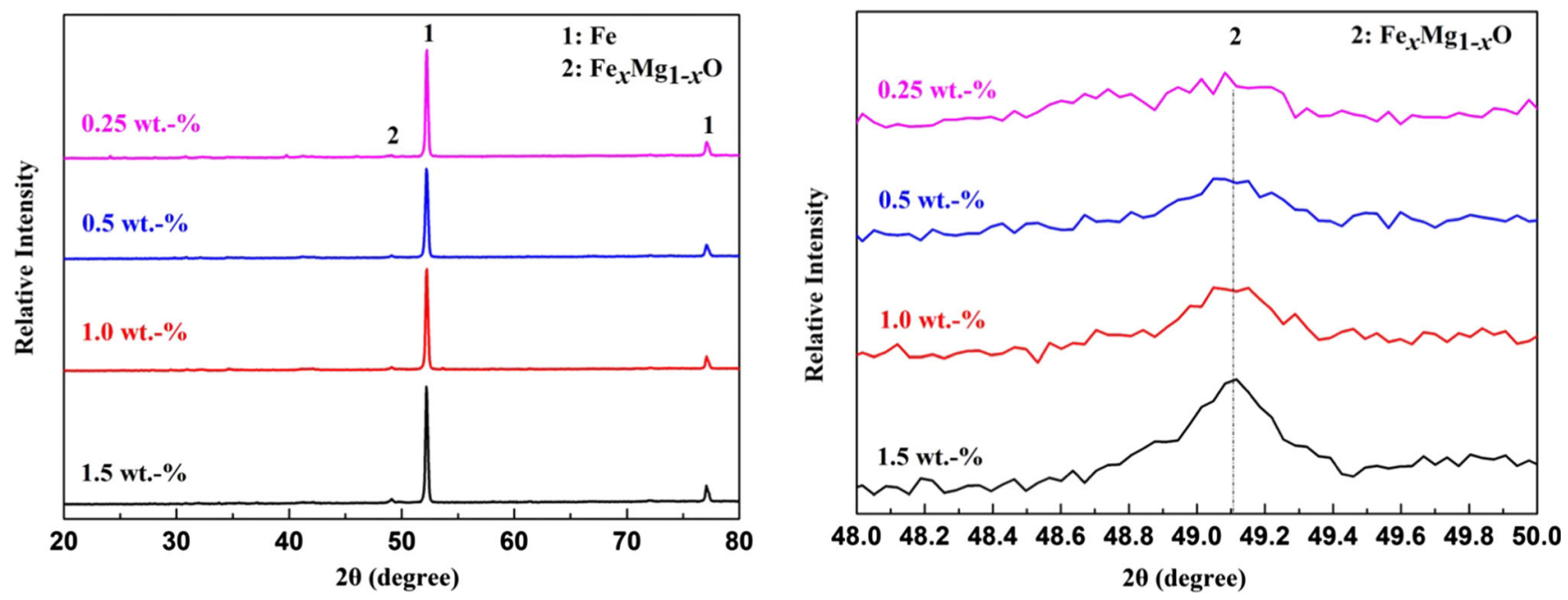

1: Fe (PDF card Reference No. 00-006-0696); 2: $\mathrm{Fe}_{x} \mathrm{Mg}_{1-x} \mathrm{O}$ (PDF card Reference No. 01-077-2369)

(a)

(b)

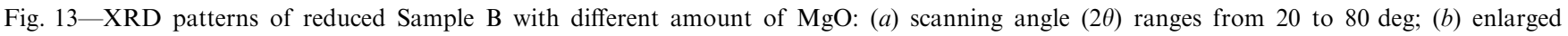
scanning angel $(2 \theta)$ between 48 and 50 deg.

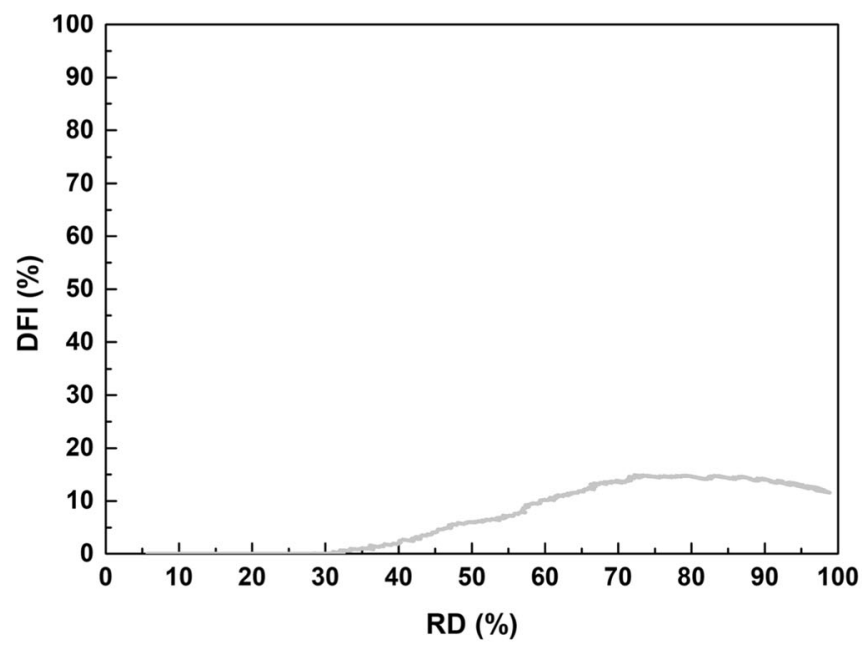

(a)

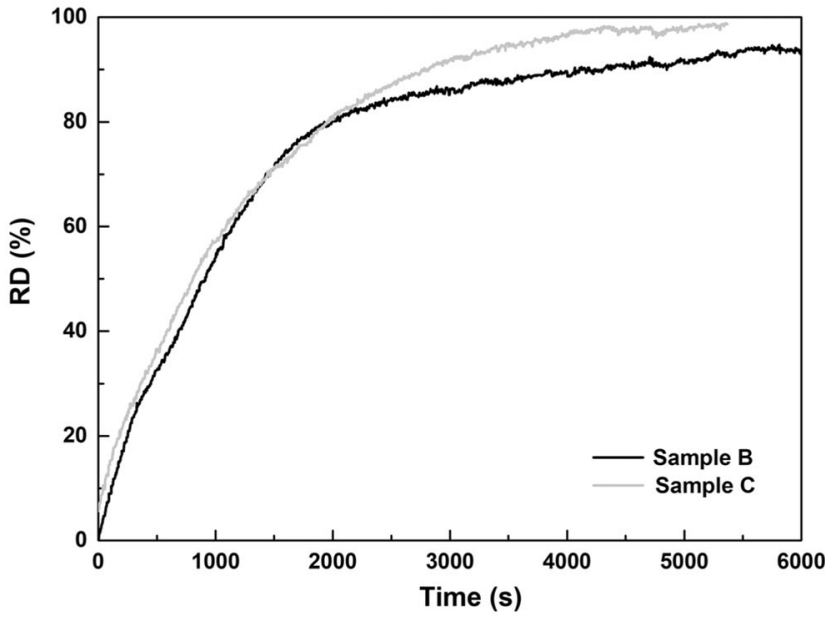

(b)

Fig. 14-Fluidization and reduction behaviors of Sample B and Sample C With 0.5 wt pet MgO addition: (a) DFI of Sample C; $(b)$ reduction degree.

given in at. pct, are listed in Table V. The EDS analysis shows that the particle surface contains $\mathrm{Fe}, \mathrm{Mg}$, and $\mathrm{O}$, indicating that the compound on the surface is composed of oxides and metallic iron. It is found that with the additional amount of $\mathrm{MgO}$, the $\mathrm{Mg}$ element on the particle surface increases. In a similar way, the oxygen content increases. The particle surface is covered by scale-like iron-containing grains. If $0.25 \mathrm{wt}$ pct $\mathrm{MgO}$ was added, the grains showed a better connection with each other, forming a network structure. With the increased content of $\mathrm{MgO}$, the grains became smaller. Therefore, these scale-like grains are regarded as a critical structure. The total area of the grains can be treated as an effective sticking area during fluidization. $\mathrm{MgO}$ prevents the growth of such grain structures by hindering lattice expansion during the oxide reduction and slowed down the diffusion rate of iron ions, ${ }^{[41]}$ which results in decreasing the contact chance of the sticky surface.

Figure 12 shows a polished cross section of Sample B with 1.5 wt pet $\mathrm{MgO}$ after reduction. The element contents of the particle from the edge to the inside is shown in Table VI. The Mg element was distributed around a seam at the particle surface, which indicates that effect of $\mathrm{MgO}$ is mainly exerted on the surface of the particles. No $\mathrm{Mg}$ element is observed inside the particle. The high content of the element $\mathrm{O}$ inside the particle was caused by the preparation of the samples. The re-oxidation of iron may occur during mounting and polishing procedures. 

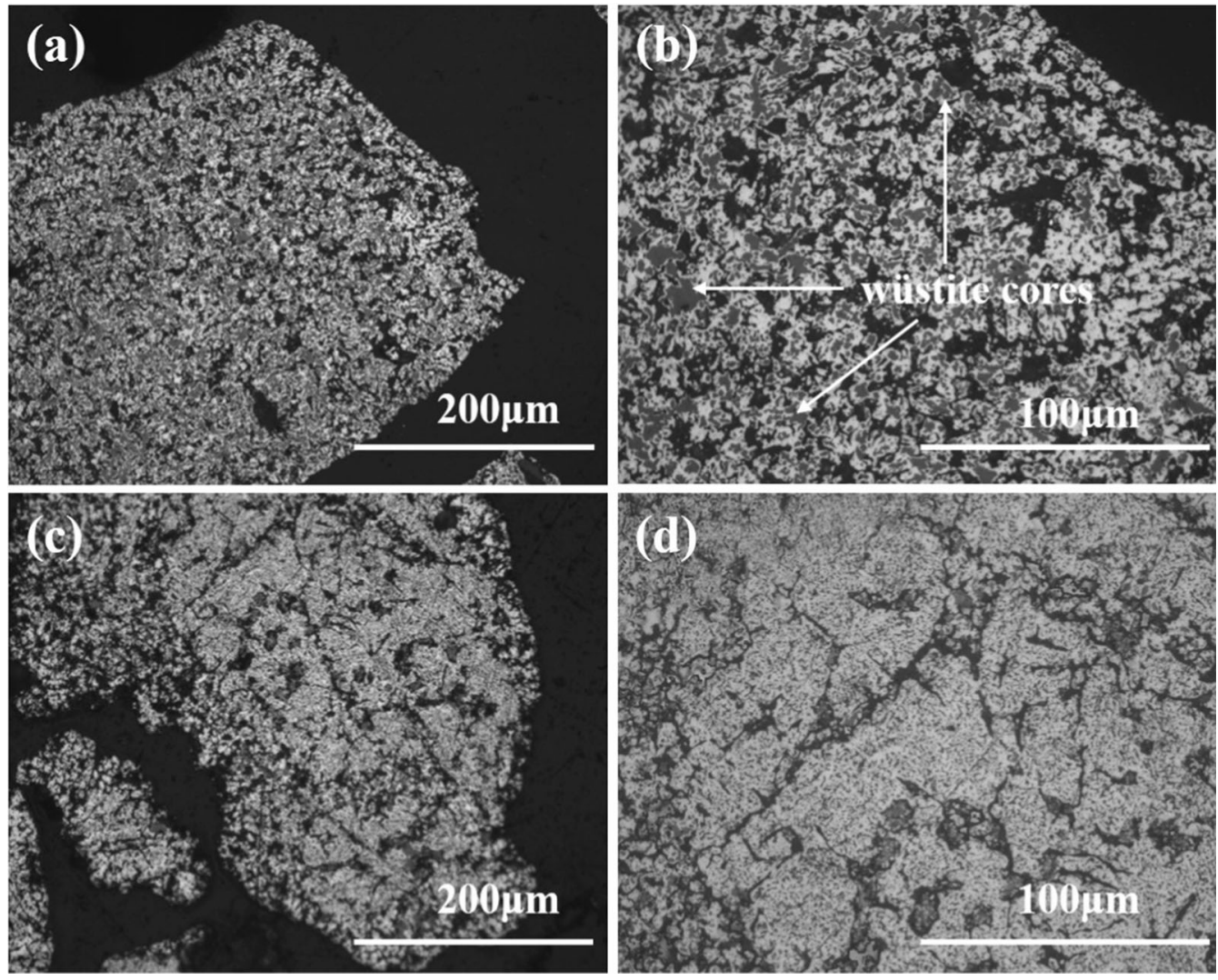

Fig. 15-Polished section images of the Sample B and Sample C after reduction tests at $700{ }^{\circ} \mathrm{C}$ with 0.5 wt pet $\mathrm{MgO}$ addition under optical light microscope: (a), (b) Sample B; (c), (d) Sample C.

Figure 13 shows the XRD results of the reduced Sample B with different amounts of $\mathrm{MgO}$-addition. It can be seen from Figure 13(a), the main phases of the reduced samples are metallic iron. As shown in Figure 13(b), due to the low amount, the peak intensities of magnesiowüstite $\left(\mathrm{Fe}_{x} \mathrm{Mg}_{1-x} \mathrm{O}\right)$ phase are quite small compared with that of iron but increases with the addition amounts of $\mathrm{MgO} . \mathrm{MgO}$ can be completely dissolved into $\mathrm{FeO}$ and form a continuous solid solution. ${ }^{[42,43]}$ The iron whiskers generally grow on the wüstite during the reduction. ${ }^{[36,44]}$ The formation of magnesiowüstite phase inhibits the further reduction of wüstite at the particle surface, thus prevents the formation of iron whiskers and scale-like iron-containing grains.

\section{Effect of Prior Partial Oxidation on the Fluidization and Reduction Behavior of Magnetite Iron Ore}

Considering the low reaction rate in the final stage of reduction, as discussed in Section III-A, the improvement by replacing deep oxidation to partial oxidation treatment is discussed. Figure 14 shows the DFI and $\mathrm{RD}$ curves of the reduction tests at $700{ }^{\circ} \mathrm{C}$ with 0.5 wt pet $\mathrm{MgO}$ addition for Sample B and Sample C. As shown in Figure 14(a), with prior partial oxidation treatment and 0.5 wt pet $\mathrm{MgO}$ addition, only about 10 pct material becomes de-fluidized. Figure 14(b) compares the reduction process of the Sample B (completed fluidized) and the Sample C ( 10 pct de-fluidization).
The reduction behavior Sample $\mathrm{C}$ is similar to that of Sample B until RD equals $\sim 80$ pct and shows a higher reduction rate during the final stage of reduction. As a result, it takes less time for Sample $\mathrm{C}$ to get nearly complete reduced.

Figure 15 shows the polished section images of the Sample B and Sample C after reduction tests at $700{ }^{\circ} \mathrm{C}$ with 0.5 wt pet $\mathrm{MgO}$ addition. For Sample B, small wüstite cores, which are covered by iron shells, can be observed inside the particles. The shells avoid the reducing gas diffuse into the particles resulting in a low reduction rate at the final stage. While the particles of Sample C were nearly completely reduced and no obvious wüstite cores can be found, which explained why Sample C shows higher reduction rate at final stage. Kinetic analyses should explain the reason for the differences.

\section{Multistep Kinetic Analysis}

The fluidization behavior of the raw magnetite-based iron ore is improved significantly by the prior oxidation treatment and the addition of $\mathrm{MgO}$. As discussed above, it seems that $\mathrm{MgO}$ promotes the initial reaction and prior partial oxidation treatment shows more beneficial reduction rates compared to a prior deep oxidation treatment. In order to investigate the mechanism behind, a multistep kinetic analysis is carried out based on the model, developed by Johnson-Mehl-Avrami. ${ }^{[45-48]}$ 


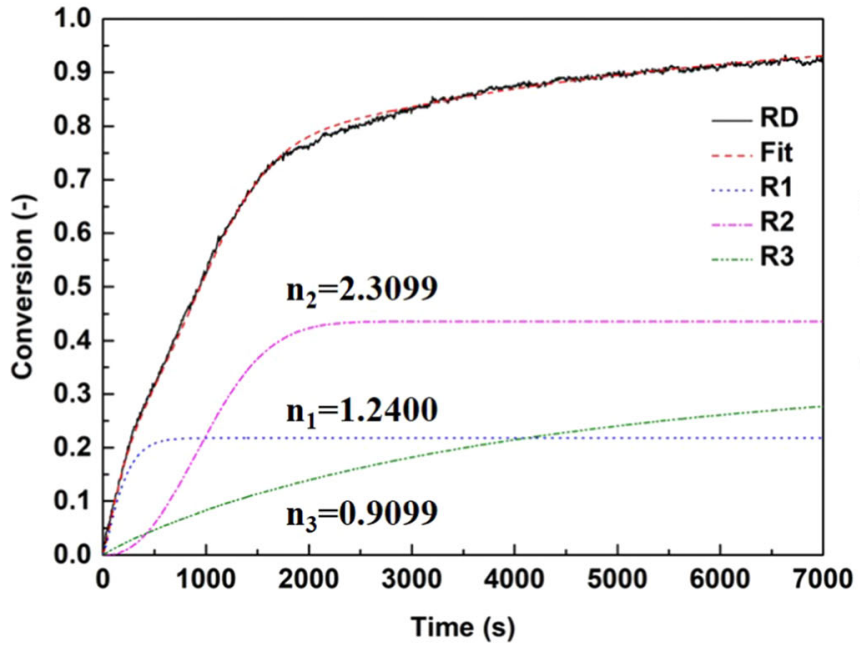

(a)

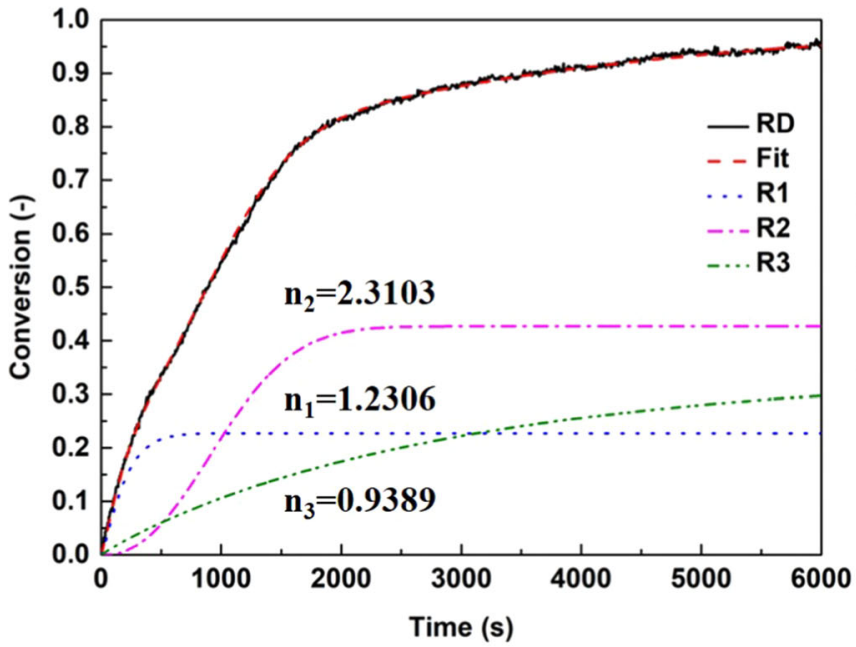

(c)

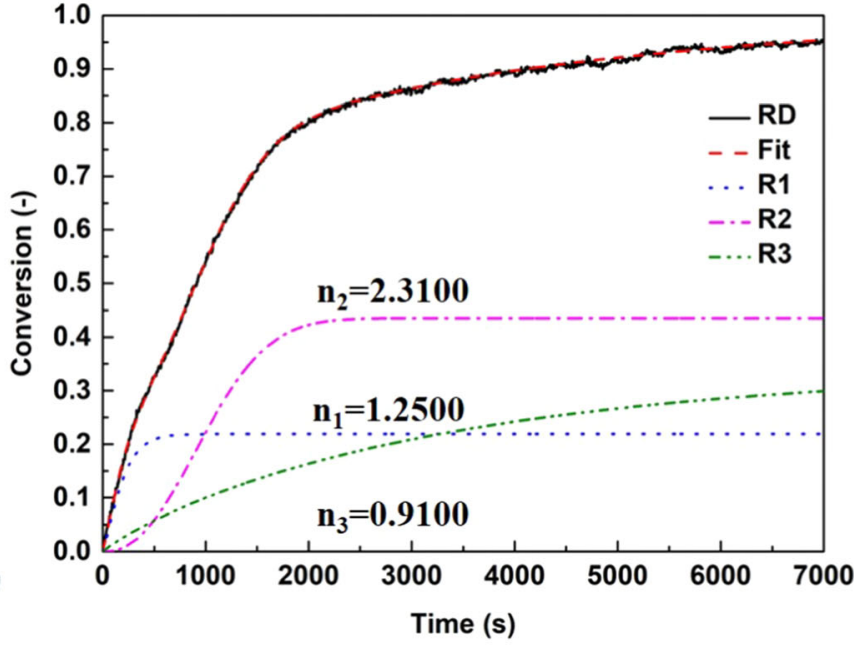

(b)

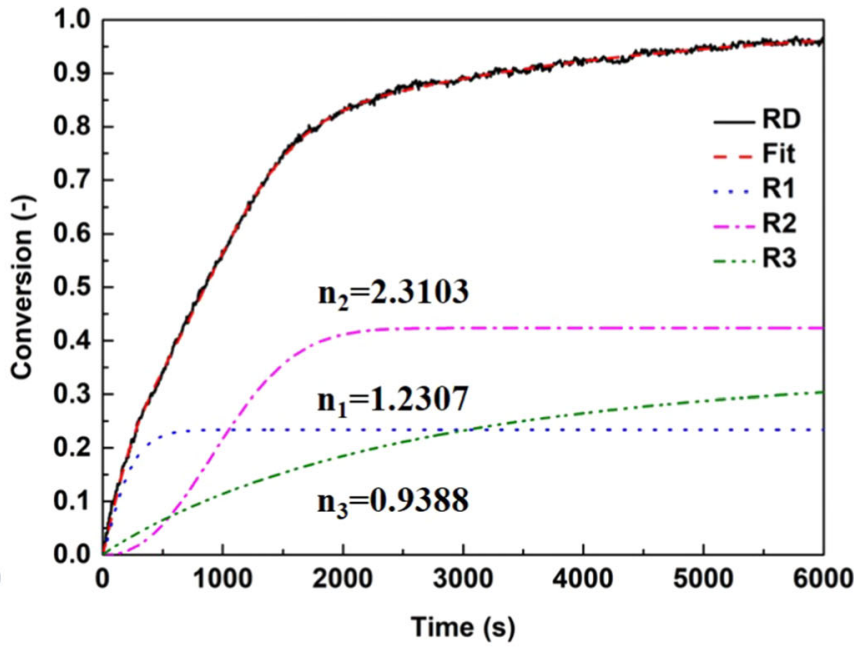

(d)

Fig. 16 - Fitting results for Sample B with different amount of MgO: (a) 0.25 wt pct; $(b) 0.5$ wt pct; $(c) 1.0$ wt pet; (d) 1.5 wt pet.

Table VII. Kinetic Analysis for Sample B With Different Amount of MgO

\begin{tabular}{|c|c|c|c|c|c|}
\hline & & \multicolumn{4}{|c|}{$\mathrm{MgO}$ Addition } \\
\hline & & $0.25 \mathrm{Wt}$ Pct & $0.5 \mathrm{Wt}$ Pct & $1.0 \mathrm{Wt} \mathrm{Pct}$ & $1.5 \mathrm{Wt}$ Pct \\
\hline \multirow[t]{3}{*}{ Weight Factors } & $w_{1}$ & 0.2180 & 0.2190 & 0.2273 & 0.2340 \\
\hline & $w_{2}$ & 0.4361 & 0.4356 & 0.4268 & 0.4235 \\
\hline & $w_{3}$ & 0.3459 & 0.3454 & 0.3459 & 0.3425 \\
\hline \multirow[t]{3}{*}{ Nucleation Rate Constants $\left(\mathrm{s}^{-1}\right)$} & $a_{1}$ & 0.0013 & 0.0013 & 0.0014 & 0.0014 \\
\hline & $a_{2}$ & $8.40 \times 10^{-8}$ & $8.40 \times 10^{-8}$ & $8.40 \times 10^{-8}$ & $8.40 \times 10^{-8}$ \\
\hline & $a_{3}$ & $5.12 \times 10^{-4}$ & $6.37 \times 10^{-4}$ & $5.60 \times 10^{-4}$ & $6.18 \times 10^{-4}$ \\
\hline \multirow[t]{3}{*}{ Kinetic Exponents } & $n_{1}$ & 1.2400 & 1.2500 & 1.2306 & 1.2307 \\
\hline & $n_{2}$ & 2.3099 & 2.3100 & 2.3103 & 2.3103 \\
\hline & $n_{3}$ & 0.9099 & 0.9100 & 0.9389 & 0.9388 \\
\hline Root Mean Square Deviation & RMSD & 0.0072 & 0.0050 & 0.0050 & 0.0046 \\
\hline
\end{tabular}


The parallel reaction process can be defined as shown in Eq. [6]. The root mean square deviation (RMSD) is used to assess the fitting procedure- the smaller RMSD, the better the fitting result. ${ }^{[8,10]}$

$$
x_{t}=w_{1}\left(1-e^{-a_{1} t^{n_{1}}}\right)+w_{2}\left(1-e^{-a_{2} t^{n_{2}}}\right)+w_{3}\left(1-e^{-a_{3} t^{n_{3}}}\right),
$$

where $w_{1,2,3}$ are the weight factors representing the relative importance of the resulting rate limiting mechanism; $a_{1,2,3}$ are the nucleation rate constants; $n_{1,2,3}$ are the kinetic exponents which can be linked to the occurring rate-limiting mechanism. If $n<1$, the rate-limiting step is considered to be diffusion controlled; If $n$ is close to 1 , the reaction mechanism belongs to the reaction kinetics; If $n>1.5$ the reaction is controlled by the nucleation process. Based on the definition of reduction degree (RD), the $\mathrm{Fe}_{2} \mathrm{O}_{3}, \mathrm{Fe}_{3} \mathrm{O}_{4}, \mathrm{FeO}$ and $\mathrm{Fe}$ exhibit the RDs of $0,11.1$ pct, 33.3 pct and 100 pct, respectively. A similar kinetics analysis procedure was used by Chen et al.[49] and Monazam et al.[50] for the reduction of $\mathrm{Fe}_{2} \mathrm{O}_{3}$ to $\mathrm{Fe}$ by $\mathrm{CO}$ and $\mathrm{CH}_{4}$, respectively, where $w$ was fixed to a certain $\mathrm{RD}$ or $n$ was fixed to a certain rate limiting mechanism. In the present study, both $w$ and $n$ were not fixed to a specific value to be able to analyze if more than one rate limiting step acts together in parallel. ${ }^{[8,10]}$

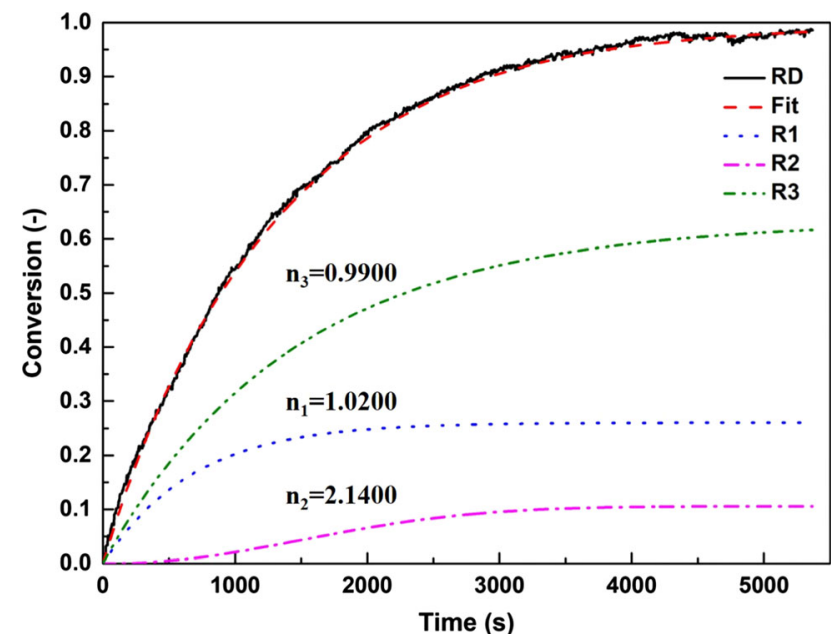

Fig. 17-Fitting results for Sample $\mathrm{C}$ with 0.5 wt pet $\mathrm{MgO}$ addition.
1. Deep Oxidized Magnetite-Based Iron Ore with Different Amounts of $\mathrm{MgO}$-Addition

Figure 16 shows the fitting results for Sample B with different amounts of $\mathrm{MgO}$-addition, where $\mathrm{R} 1, \mathrm{R} 2$ and $\mathrm{R} 3$ represent chemical reaction, nucleation and diffusion respectively. It should be noticed that in case of 0.25 wt pet $\mathrm{MgO}$ addition, around 10 pet of the material was not fluidized. The results fit very well to the experimental data as shown by the low RMSD values in Table VII. It can be seen that the reaction process $\mathrm{R} 1$ dominates the initial portion of the total RD. Hence, R1 will have little influence on the later reduction stage. In terms of long-time reaction processes, the total $\mathrm{RD}$ is dominated by $\mathrm{R} 2$ and $\mathrm{R} 3$. The values of $w_{1}$ slightly increase with the amount of $\mathrm{MgO}$-addition, representing the promotion effect of the reaction in the initial stage. The values of $w_{2}$ and $w_{3}$ show a small decline trends but keep quite stable. In general, the amount of $\mathrm{MgO}$ has little influence on the reaction mechanisms. The parallel reaction processes can be described as follows. More than one rate limiting step acts together in parallel in each reduction stage. The fast-chemical reaction dominates the initial reduction stage, where the $\mathrm{Fe}_{2} \mathrm{O}_{3}$ is reduced into $\mathrm{Fe}_{3} \mathrm{O}_{4}$. While nucleation and diffusion rule the middle reduction stage, but nucleation is in a dominant position. The reduction from $\mathrm{Fe}_{3} \mathrm{O}_{4}$ to $\mathrm{FeO}$ is mainly controlled by nucleation. After an incubation time for the nucleation of metallic iron, in the later reaction, nucleation is not important anymore. The diffusion becomes the reaction limiting step, which is in good agreement with Figures 15(a) and (b), where small remaining wüstite cores are cover by dense iron shells.

\section{Partly oxidized magnetite-based iron ore with 0.5} wt pet $\mathrm{MgO}$ addition

Figure 17 shows the fitting result of partly Sample C with 0.5 wt pct $\mathrm{MgO}$-addition. The reaction mechanism experienced a significant change comparing with that of Sample B (Figure 16(b)). It can be seen that the reaction process $\mathrm{R} 3$ and $\mathrm{R} 1$ dominate the total $\mathrm{RD}$, especially in the initial stage. Since $n_{3}$ and $n_{1}$ are close to 1 , the reaction process $\mathrm{R} 3$ and $\mathrm{R} 1$ are both considered to be chemical reaction. Hence, diffusion is not the limiting step anymore, which is in good agreement with the Figures 15(c) and (d), where nearly no small unreacted wüstite cores can be found. The reaction is mainly controlled by the chemical reaction, also at the later stage. In the middle reduction stage, nucleation still plays the limiting role but not as big as that in Sample B. Table VIII shows the kinetic analysis result. Compared with Sample B, the value of $w_{1}$ and $w_{3}$ are much higher, representing that the prior partial oxidation promotes both the diffusion and the chemical reaction.

Table VIII. Kinetic Analysis for Sample C with 0.5 Wt Pct MgO-Addition

\begin{tabular}{llllll}
\hline & \multicolumn{1}{c}{ Partly Oxidized Magnetite Iron Ore with 0.5 wt pct MgO Addition } & RMSD \\
\hline$w_{1}$ & 0.2608 & $a_{1}$ & $1.31 \times 10^{-3}$ & $n_{1}$ & 1.0200 \\
$w_{2}$ & 0.1060 & $a_{2}$ & $8.41 \times 10^{-8}$ & $n_{2}$ & 2.1400 \\
$w_{3}$ & 0.6332 & $a_{3}$ & $7.38 \times 10^{-4}$ & $n_{3}$ & 0.9900 \\
\hline
\end{tabular}




\section{CONCLUSIONS}

The purpose of this research work is to use magnetite-based iron ore directly for hydrogen-induced fluidized bed reduction and examine methods preventing de-fluidization. The effect of a prior oxidation treatment is discussed and the $\mathrm{MgO}$ is examined to prevent de-fluidization. The following conclusions are obtained:

(1) The raw magnetite-based iron ore without pretreatment could not be successful fluidized during the reduction experiments. The newly formed metallic iron agglomerated on the surface of the magnetite particle and an iron shell is formed surrounding a dense wüstite core. At $600{ }^{\circ} \mathrm{C}$, de-fluidization could be avoided by a prior deep oxidation treatment. After oxidation, the phase structure during reduction became porous. This porous structure allows the reducing gas to penetrate into the particle resulting in a higher reduction rate until certain degrees of reduction and decreasing the aggregation of metallic iron on the surface.

(2) At a higher reduction temperature, the inhibition effect of prior deep oxidation was reduced. An addition of at least $0.5 \mathrm{wt}$ pet $\mathrm{MgO}$ was required to maintain complete fluidization. After reduction, the particle surface of the sample doped with $\mathrm{MgO}$ shows a quite smooth structure instead of whiskers. The formation of magnesiowüstite $\left(\mathrm{Fe}_{x} \mathrm{Mg}_{1-x} \mathrm{O}\right)$ phase inhibits the further reduction of wüstite at the particle surface, thus prevents the formation of iron whiskers and the growth of scale-like iron-containing grains on the particle surface.

(3) Although the fluidization state was improved by deep prior oxidation treatment, the reduction rate dramatically decreased in the final reduction period because of the unreacted wüstite cores inside the particles. This problem could be improved via replacing prior deep oxidation by a partial oxidation treatment. These two kinds of samples have similar reduction behaviors until RDs approximate 80 pct, the partly oxidized sample showed higher reduction rates during the final stage of reduction. As a result, it takes less time to get a nearly complete reduction. The optimum pretreatment for magnetite-based iron ore during hydrogen-induced fluidized bed reduction is considered to be a prior partial oxidation combined with an addition of $\mathrm{MgO}$. The prior oxidation temperature may also influence the reduction behaviors, which will be investigated in the future work.

(4) $\mathrm{MgO}$ could promote the initial reaction because of an increase in active sites owing to the $\mathrm{Mg}^{2+}$ cations into $\mathrm{Fe}_{2} \mathrm{O}_{3}$ lattice. At later reduction stages, the formation of magnesiowüstite slows down the reduction rate. Generally, in the present experimental conditions, the addition of $\mathrm{MgO}$ shows a promotion effect on the reduction rate. For deep oxidized sample, the amount of $\mathrm{MgO}$ addition has little influence on the occurring rate-limiting mechanisms. The chemical reaction dominates the initial reaction. The diffusion becomes the reaction limiting step in the final stage. The occurring rate-limiting mechanisms of the partly oxidized sample are totally different compared to the deep oxidized sample. The chemical reaction dominates the reduction process. The reaction rate limiting step is no longer diffusion but chemical reaction.

\section{ACKNOWLEDGMENTS}

The authors gratefully acknowledge the funding support of K1-MET GmbH, metallurgical competence center. The research program of the K1-MET competence center is supported by COMET (Competence Center for Excellent Technologies), the Austrian program for competence centers. COMET is funded by the Federal Ministry for Climate Action, Environment, Energy, Mobility, Innovation and Technology, the Federal Ministry for Digital and Economic Affairs, the provinces of Upper Austria, Tyrol and Styria and the Styrian Business Promotion Agency (SFG). In addition, the research work is partially financed by Montanuniversitaet Leoben. Zheng Heng greatly acknowledges the financial support from the program of China Scholarship Council (No.201908420284).

\section{FUNDING}

Open access funding provided by Montanuniversität Leoben.

\section{OPEN ACCESS}

This article is licensed under a Creative Commons Attribution 4.0 International License, which permits use, sharing, adaptation, distribution and reproduction in any medium or format, as long as you give appropriate credit to the original author(s) and the source, provide a link to the Creative Commons licence, and indicate if changes were made. The images or other third party material in this article are included in the article's Creative Commons licence, unless indicated otherwise in a credit line to the material. If material is not included in the article's Creative Commons licence and your intended use is not permitted by statutory regulation or exceeds the permitted use, you will need to obtain permission directly from the copyright holder. To view a copy of this licence, visit http://creativec ommons.org/licenses/by/4.0/. 


\section{REFERENCES}

1. K. He and L. Wang: Renew. Sustain. Energy Rev., 2017, vol. 70, pp. 1022-39.

2. World Steel Association: Climate change mitigation, https://www. worldsteel.org/publications/fact-sheets.html. Accessed 22 October 2020 .

3. European Commission: 2050 long-term strategy, https://ec.euro pa.eu/clima/policies/strategies/2050_en. Accessed 30 October 2020 .

4. Material Economics: Industrial transformation 2050 - pathways to net-zero emissions from EU heavy industry, 2019, pp. 68-75 h ttps://media.sitra.fi/2019/05/30150529/industrial-transformation-2 050.pdf. Accessed 30 October 2020.

5. Columbia Climate Center: Mitigating iron and steel emissions, $h$ ttps://www.yumpu.com/en/document/read/8268353/mitigating-iro n-and-steel-emissions, Accessed 30 October 2020.

6. J. Rissman, C. Bataille, E. Masanet, N. Aden, W.R. Morrow, III, N. Zhou, N. Elliott, R. Dell, N. Heeren, and B. Huckestein: Appl. Energy, 2020, vol. 266, art. no. 114848.

7. B. Stelter, R. Haslehner, and N. Osio: Steel as a Model for a Sustainable Metal Industry in 2050, https://www.bcg.com/publica tions/2015/metals-mining-sustainability-steel-as-a-model-for-a-sus tainable-metal-industry-in-2050. Accessed 30 October 2020.

8. D. Spreitzer and J. Schenk: Metall. Mater. Trans. B, 2019, vol. 50B, pp. 2471-94.

9. J. Schenk: Particuology, 2011, vol. 9, pp. 14-23.

10. D. Spreitzer and J. Schenk: Particuology, 2020, vol. 52, pp. 36-46.

11. E. Park and O. Ostrovski: ISIJ Int., 2004, vol. 44, pp. 74-81.

12. E. Park and O. Ostrovski: ISIJ Int., 2004, vol. 44, pp. 999-1005.

13. Z.Y. Wang, J.L. Zhang, K.X. Jiao, Z.J. Liu, and M. Barati: J. Alloy. Compd., 2017, vol. 729, pp. 874-83.

14. B. Zhang, X.Z. Gong, Z. Wang, and Z.C. Guo: ISIJ Int., 2011, vol. 51, pp. 1403-09.

15. H.J. Shao, Z.C. Guo, and H.Q. Tang: ISIJ Int., 2011, vol. 51, pp. $1290-95$.

16. Y.W. Zhong, Z. Wang, Z. Guo, and Q. Tang: Powder Technol., 2012, vol. 230, pp. 225-31.

17. Y.W. Zhong, J.T. Gao, Z. Wang, and Z.C. Guo: ISIJ Int., 2017, vol. 57, pp. 649-55.

18. X.Z. Gong, B. Zhang, Z. Wang, and Z.C. Guo: Metall. Mater. Trans. B, 2019, vol. 50B, pp. 2471-94

19. F. Lu, L.Y. Wen, X. Han, W.H. Jiang, H.M. Duan, J. Xu, and S.F. Zhang: J. Iron. Steel Res. Int., 2019, vol. 26, pp. 829-37.

20. Z. Du, Q.S. Zhu, C.L. Fan, F. Pan, H.Z. Li, and Z.H. Xie: Steel Res. Int., 2016, vol. 87, pp. 789-97.

21. L. Guo, H. Gao, J.T. Yu, Z.L. Zhang, Z.C. Guo: Int. J. Miner Metall. Mater, 2015, vol. 22, pp. 12-20.

22. Y.W. Zhong, Z. Wang, Z.C. Guo, and Q. Tang: Powder Technol., 2013, vol. 241, pp. 142-48.

23. H.J. Shao, Z.C. Guo, and H. Tang: Steel Res. Int., 2013, vol. 84, pp. $111-18$.
24. L. Guo, J. Tang, H. Tang, Z.C. Guo: Mater. Today: Proc., vol. 2, pp. S332-S341.

25. L. Guo, Y.W. Zhong, J.T. Gao, Z.R. Yang, and Z.C. Guo: Powder Technol., 2015, vol. 284, pp. 210-17.

26. Z. Du, Q.S. Zhu, Y.F. Yang, C.L. Fan, F. Pan, H.Y. Sun, and Z.H. Xie: Steel Res. Int., 2016, vol. 87, pp. 1742-49.

27. L. Guo, Q.P. Bao, J.T. Gao, Q.S. Zhu, and Z.C. Guo: ISIJ Int., 2020, vol. 60, pp. 1-17.

28. A. Pichler, H. Mali, F. Plaul, J. Schenk, M. Skorianz, and B. Weiss: Steel Res. Int., 2016, vol. 87, pp. 642-52.

29. M. Skorianz, H. Mali, A. Pichler, F. Plaul, J. Schenk, and B. Weiss: Steel Res. Int., 2016, vol. 87, pp. 633-41.

30. D. Spreitzer: Development of characterization methods for the evalution of kinetic behavior and the fluidization of iron ore fines during hydrogen-induced fluidized bed reduction, Montanuniversitaet Leoben, PhD thesis, unpublished research, 2020.

31. A.A. Adetoro, H.Y. Sun, S.Y. He, Q.S. Zhu, and H.Z. Li: Metall. Mater. Trans. B, 2018, vol. 49B, pp. 846-57.

32. K.S. Zhu, Y.L. Fu: J. Anhui Univ. Technol. (Natural Science), 1992, pp. 21-25.

33. S. Hayashi, S. Sawai, and Y. Iguchi: ISIJ Int., 1993, vol. 33, pp. 1078-87.

34. Z.Y. Zhong, Z. Wang, Z. Guo, and Q. Tang: Powder Technol., 2014, vol. 256, pp. 13-19.

35. YW Zhong, XZ Gong, Z Wang, and ZC Guo: J. Univ. Sci. Technol. Beijing, 2011, vol. 33, pp. 406-12.

36. R. Nicolle and A. Rist: Metall. Mater. Trans. B, 1979, vol. 10B, pp. 429-38.

37. M.I.A. Barustan and S.M. Jung: Met. Mater. Int., 2019, vol. 25, pp. 1083-97.

38. S. Dwarapudi, T.K. Ghosh, V. Tathavadkar, and M.B. Denys: Int. J. Miner. Process., 2012, vols. 112-113, pp. 55-62.

39. J.L. Li: Study on the surface morphology and the growth of iron crystal in the fluidized reduction process, Chongqing University, Master thesis, 2017.

40. A.A.EI-Geassy: Ironmaking Steelmaking, 1999, vol. 26, pp. 41-52.

41. K.S.A. Halim, M. Bahgat, H.A. El-Kelesh, and M.I. Nasr: Ironmak. Steelmak., 2009, vol. 36, pp. 631-40.

42. I. Strandkvist, A. Sandstrom, and F. Engstrom: Steel Res. Int., 2017, vol. 88, p. 1600322.

43. K. Narita, M. Maekawa, I. Shigaki, and Y. Seki: Tetsu to Hagane, 1977, vol. 10, pp. 1623-32.

44. L. Guo, Q.P. Bao, J.T. Gao, Q.S. Zhu, and Z.C. Guo: ISIJ Int., 2020, vol. 60 , pp. $1-17$

45. W.A. Johnson and R.F. Mehl: Trans. Am. Inst. Min. Metall. Eng, 1940, vol. 135, pp. 416-42.

46. MP Avrami: J. Chem. Phys., 1939, vol. 7, pp. 1103-12.

47. M.P. Avrami: J. Chem. Phys., 1940, vol. 8, pp. 212-24.

48. M.P. Avrami: J. Chem. Phys, 1941, vol. 9, pp. 177-84.

Publisher's Note Springer Nature remains neutral with regard to jurisdictional claims in published maps and institutional affiliations. 